\title{
Investigation of a Macromechanical Approach to Analyzing Triaxially-Braided Polymer Composites
}

Robert K. Goldberg

Glenn Research Center, Cleveland, Ohio

Brina J. Blinzler and Wieslaw K. Binienda

University of Akron, Akron, Ohio 


\section{NASA STI Program . . . in Profile}

Since its founding, NASA has been dedicated to the advancement of aeronautics and space science. The NASA Scientific and Technical Information (STI) program plays a key part in helping NASA maintain this important role.

The NASA STI Program operates under the auspices of the Agency Chief Information Officer. It collects, organizes, provides for archiving, and disseminates NASA's STI. The NASA STI program provides access to the NASA Aeronautics and Space Database and its public interface, the NASA Technical Reports Server, thus providing one of the largest collections of aeronautical and space science STI in the world. Results are published in both non-NASA channels and by NASA in the NASA STI Report Series, which includes the following report types:

- TECHNICAL PUBLICATION. Reports of completed research or a major significant phase of research that present the results of NASA programs and include extensive data or theoretical analysis. Includes compilations of significant scientific and technical data and information deemed to be of continuing reference value. NASA counterpart of peer-reviewed formal professional papers but has less stringent limitations on manuscript length and extent of graphic presentations.

- TECHNICAL MEMORANDUM. Scientific and technical findings that are preliminary or of specialized interest, e.g., quick release reports, working papers, and bibliographies that contain minimal annotation. Does not contain extensive analysis.

- CONTRACTOR REPORT. Scientific and technical findings by NASA-sponsored contractors and grantees.
- CONFERENCE PUBLICATION. Collected papers from scientific and technical conferences, symposia, seminars, or other meetings sponsored or cosponsored by NASA.

- SPECIAL PUBLICATION. Scientific, technical, or historical information from NASA programs, projects, and missions, often concerned with subjects having substantial public interest.

- TECHNICAL TRANSLATION. Englishlanguage translations of foreign scientific and technical material pertinent to NASA's mission.

Specialized services also include creating custom thesauri, building customized databases, organizing and publishing research results.

For more information about the NASA STI program, see the following:

- Access the NASA STI program home page at http://www.sti.nasa.gov

- E-mail your question via the Internet to help@ sti.nasa.gov

- Fax your question to the NASA STI Help Desk at 443-757-5803

- Telephone the NASA STI Help Desk at 443-757-5802

- Write to: NASA Center for AeroSpace Information (CASI) 7115 Standard Drive Hanover, MD 21076-1320 


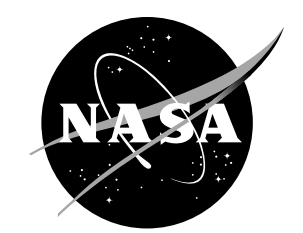

\section{Investigation of a Macromechanical Approach to Analyzing Triaxially-Braided Polymer Composites}

Robert K. Goldberg

Glenn Research Center, Cleveland, Ohio

Brina J. Blinzler and Wieslaw K. Binienda

University of Akron, Akron, Ohio

Prepared for the

51th Structures, Structural Dynamics, and Materials Conference

cosponsored by the AIAA, ASME, ASCE, AHS, and ASC

Orlando, Florida, April 12-15, 2010

National Aeronautics and

Space Administration

Glenn Research Center

Cleveland, Ohio 44135 


\section{Acknowledgments}

This work was funded by the Aging Aircraft and Durability Program of the Aviation Safety Project.

Trade names and trademarks are used in this report for identification only. Their usage does not constitute an official endorsement, either expressed or implied, by the National Aeronautics and Space Administration.

Level of Review: This material has been technically reviewed by technical management.

Available from

NASA Center for Aerospace Information 7115 Standard Drive

Hanover, MD 21076-1320
National Technical Information Service 5301 Shawnee Road Alexandria, VA 22312

Available electronically at http://gltrs.grc.nasa.gov 


\title{
Investigation of a Macromechanical Approach to Analyzing Triaxially-Braided Polymer Composites
}

\author{
Robert K. Goldberg \\ National Aeronautics and Space Administration \\ Glenn Research Center \\ Cleveland, Ohio 44135 \\ Brina J. Blinzler and Wieslaw K. Binienda \\ University of Akron \\ Akron, Ohio 44325
}

\begin{abstract}
A macro level finite element-based model has been developed to simulate the mechanical and impact response of triaxially-braided polymer matrix composites. In the analytical model, the triaxial braid architecture is simulated by using four parallel shell elements, each of which is modeled as a laminated composite. The commercial transient dynamic finite element code LS-DYNA is used to conduct the simulations, and a continuum damage mechanics model internal to LS-DYNA is used as the material constitutive model. The material stiffness and strength values required for the constitutive model are determined based on coupon level tests on the braided composite. Simulations of quasi-static coupon tests of a representative braided composite are conducted. Varying the strength values that are input to the material model is found to have a significant influence on the effective material response predicted by the finite element analysis, sometimes in ways that at first glance appear non-intuitive. A parametric study involving the input strength parameters provides guidance on how the analysis model can be improved.
\end{abstract}

\section{Introduction}

The use of textile (woven and braided) polymer composites is being actively investigated for potential application in aerospace structures, as an alternative to metals or traditional laminated composites. For example, triaxially-braided composites are being utilized in fan cases for jet engines. To be certified as flight-worthy, a full-scale engine blade-out test must be performed to demonstrate that the fan containment system can contain a released fan blade and that the fan case can maintain sufficient structural integrity during the engine spool down. As part of the design process, the need exists to simulate the blade and case deformation, along with the resulting damage and failure, during a blade-out event through the use of commercial explicit finite element codes. For metallic case systems, a sufficient ability to properly simulate the blade-out event exists due to the fact that adequate material databases and engineering experience in correlating analysis and test results are available. However, the capability to simulate the impact response of composite materials is much less mature. The ultimate goal of the current research is to improve the blade-out simulation capability for composite fan cases to a level comparable to that available for metallic cases. The work presented in this paper is a step towards that goal.

There has been a significant amount of research conducted in the analysis and modeling of textile composites. The majority of the efforts have concentrated on various means to determine the effective mechanical properties of woven materials. Among the earliest attempts to model these materials was the work of Chou and Ishikawa (Ref. 1). In their original mosaic model, the woven composite was approximated as a one-dimensional series of laminated cross-ply composites, and classical laminate theory in combination with iso-stress or iso-strain assumptions were applied to obtain the effective stiffness properties of the material. They later extended the model to account for the fiber undulations that are present in an actual woven material (Ref. 1). This approach was extended to two dimensions by Naik and Shembekar (Ref. 2), where a mixture of parallel and series assumptions were applied to obtain the 
effective properties of the material. To analyze more complicated fiber architectures, such as braided composites, researchers such as Pastore and Gowayed (Ref. 3) and Byun (Ref. 4) modeled the fibers as a series of rods at various angles, and utilized simple iso-strain assumptions to obtain the overall effective properties of the composite. More sophisticated analysis methods, such as those developed by Tanov and Tabiei (Ref. 5) and Bednarcyk and Arnold (Ref. 6), used an approach where a representative unit cell of a woven composite was created, and then micromechanics-based approaches were applied to compute the effective properties and response of the material. In the context of applying these methods within a finite element model, elements are created with a homogenized set of material properties, and the appropriate analysis method is used to generate the effective properties and response of the woven material.

When many of these previously developed analytical methods have been used to conduct a finite element analysis of a structure composed of woven or braided composite materials, homogenized elements are used, in which the architecture of the textile material is not directly accounted for within the finite element model. However, for triaxially-braided composites, experimental evidence has shown (Ref. 7) that when these materials are subject to impact, oftentimes the damage will propagate along the fiber directions. To best simulate these damage patterns, the braid architecture should be directly simulated within the finite element model. To account for the fiber architecture in a computationally efficient manner, Cheng (Ref. 8) created a "Braided Through the Thickness" approach, where the braided composite is modeled as a series of layered shell elements, where each element is a laminated composite with the appropriate fiber-layup. The effective stiffness and strength material properties of the equivalent unidirectional composite then were included as input data for the finite element analysis. In the method developed by Cheng, fiber and matrix properties were combined using simple micromechanics-based approaches to obtain the required effective properties. The model was developed within the context of LS-DYNA (Ref. 9), a commercially available transient dynamic finite element code which is commonly used within the aerospace industry. A continuum damage mechanics based composite constitutive model available within LS-DYNA was used as the material model.

Littell et al. (Ref. 10) made two major extensions to the approach developed by Cheng. First of all, in actual braided composites, the layers of braid often do not directly sit on top of each other, but instead fiber nesting takes place. In this work, the phrase "fiber nesting" refers to the in-plane shifting of fibers in adjacent plies by a fraction of the unit cell dimensions, not the definition that is also sometimes used in the context of textile composites, that of through-the-thickness shifting that also sometimes occurs. In their work, the discretization of the braid was adjusted to account for this phenomenon. More significantly, in the previously developed methods, the effective unidirectional composite properties of the materials utilized in a braided composite either had to be measured experimentally or computed by using micromechanics techniques. This approach requires an extensive additional experimental program, with tests on either the matrix constituent (for micromechanics approaches) or the equivalent unidirectional composites, besides tests on the braided composite, being required to obtain the needed data. These test programs can be quite complicated, with no guarantee that the experimental properties obtained are representative of the in-situ properties of the material within the braided composite. In the approach developed by Littell, et al., the equivalent unidirectional properties of the composite were extracted based on data obtained from coupon tests of the braided composite. In this manner, the in-situ properties were directly incorporated into the input for the material model, which could reduce the amount of testing required. Also, this approach has the potential to accurately simulate the deformation, damage and failure of a triaxially-braided composite in a computationally efficient manner. Alternatively, an approach of this type can be useful as a tool to verify more sophisticated analysis approaches. As described by Littell, et al. (ref 10), the stiffness and strength values obtained through simulations of quasistatic coupon tests correlated reasonably well to experimentally obtained values. However, when flat panel impact tests were simulated, the predicted penetration velocity correlated reasonably well to experimentally obtained values for some materials and the predicted damage patterns did not correlate well to what was observed experimentally.

In this paper, first the "Braided Through the Thickness" analysis method developed by Cheng (Ref. 8) and extended by Littell, et al (Ref. 10) as applied to the analysis of triaxially-braided polymer composites 
will be summarized and explained. Next, a series of parametric studies designed to better understand how the material data input affects the computed response of the triaxially-braided material will be discussed. One of the major current goals of the research effort is to improve the ability of the analysis method to predict the damage patterns which result when a triaxially-braided composite is subject to impact loads. One approach to improving the damage predictions is to modify the strength parameters that are input into the material model. Since, as will be described later, the strength parameters are obtained from quasistatic coupon tests, rate dependence of the composite strengths needed for impact simulation are not currently accounted for within the analysis approach. Due to the nature of the constitutive model which is currently being utilized, the effects of varying a particular parameter on the overall simulations may not be straightforward. A first step in determining the sensitivity of the simulations to material model property input, the effect of varying the input strength parameters on the stress-strain curves and ultimate strength predictions obtained through simulations of quasi-static coupon tests is being quantified. Insights from this study can then be utilized to provide guidance on how the model input parameters can be varied to improve the simulation of impact events.

\section{Overview of Analysis Approach}

The "Braided Through the Thickness" analysis approach as developed by Cheng (Ref. 8) and Littell, et al (Ref. 10) has currently been designed to analyze triaxially-braided polymer composites with a $\left[0 \%+60 \%-60^{\circ}\right]$ braid architecture. Other triaxially-braided fiber architectures are currently being simulated using the approach, but theoretically the methodology can be applied to any textile composite architecture. A unit cell of a typical triaxially-braided fiber preform is shown in Figure 1(a). In the figure, the $\pm 60^{\circ}$ bias fibers are visible on the surface. Portions of the $0^{\circ}$ axial fibers that lie below the bias fibers can be seen in the open spaces between the bias fibers. An assumption in the methodology is that the fiber bundle spacing and number of fibers per fiber bundle are adjusted such that the fiber volume fractions in both the axial and bias directions are equal. In actuality, this particular fiber architecture is quasi-isotropic in-plane. Therefore the global in-plane stiffness should be the same in all directions, but this condition is not actually applied within the context of the analysis model.

To apply the analysis approach, the braided-fiber architecture is idealized. As a first step in this process, a schematic of the top view of the fiber architecture is shown in Figure 1(b), where the $-60^{\circ}$ bias fibers are green, the $+60^{\circ}$ bias fibers are red, and the $0^{\circ}$ axial fibers are blue. As shown in the figure, the unit cell can be divided into four equal length parallel subcells. Next, each subcell is approximated to be a laminated composite composed of a stack of fiber bundles at various orientations that are determined by the braid architecture. Subcell $\mathrm{A}$ is modeled as a $\left[+60^{\circ} / 0^{\circ} /-60^{\circ}\right]$ composite (bottom layer listed first). Subcell B is modeled as a $\left[+60^{\circ} /-60^{\circ}\right]$ composite, subcell C is modeled as a $\left[-60^{\circ} / 0^{\circ} /+60^{\circ}\right]$ composite, and subcell $\mathrm{D}$ is modeled as a $\left[-60^{\circ} /+60^{\circ}\right]$ composite. This idealization is shown in Figure 1(c). Each subcell can be modeled as an individual shell element in a finite element model. A unit cell then consists of four shell elements. Shell elements can be used since the length and width of the composite structures typically considered are much greater than the thickness. A full structure can then be modeled by replicating this four element unit cell throughout the finite element mesh. Each subcell is assumed to be equal thickness with a constant fiber volume fraction. In actuality, this assumption is inaccurate. In the one layer model, as described here, the plies in subcell B and subcell D should have lower overall fiber volume fractions due to the lack of axial fibers, resulting in these subcells only having two plies while subcell A and subcell C have three plies. However, this assumption simplifies the process of determining the material properties to be input into the model using the techniques to be described below. Future efforts will concentrate on modifying the analysis method to remove this assumption. Note also that while the unit cell as a whole can be approximated to be a symmetric composite, each individual subcell is not a symmetric composite. The assumption is made that since the unit cell as a whole is a symmetric composite, any normal-bending coupling will be smeared out. As a result, the portion of the laminate stiffness matrix (commonly referred to as the " $\mathrm{B}$ " matrix) that relates the in-plane loads to out-of-plane curvatures is assumed to be equal to zero. 
(a)

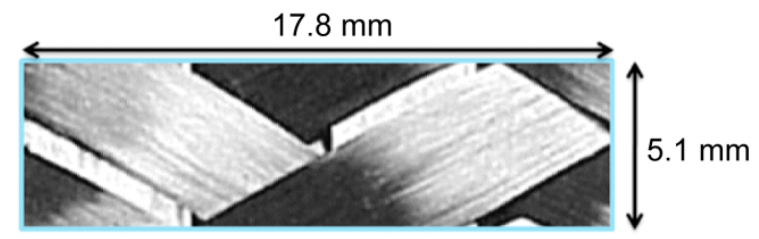

(b)

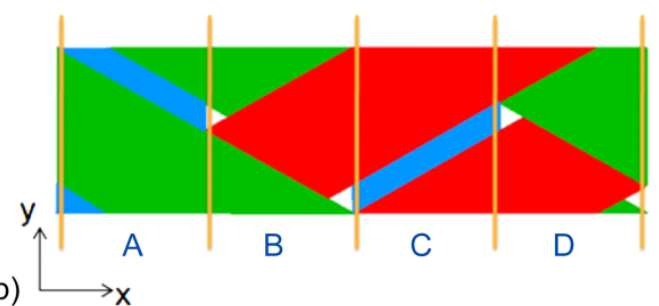

(c)

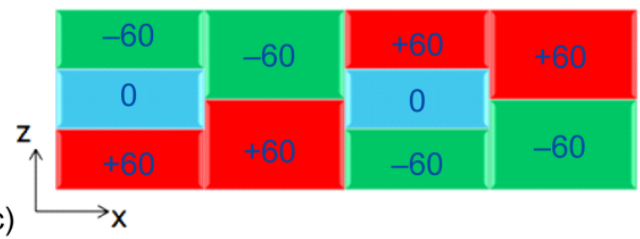

Figure 1.-Discretization of unit cell of triaxially-braided composite for braided through the thickness approach. (a) Micrograph of unit cell. (b) Identification of axial and bias fibers within the unit cell. (c) Approximation of braid architecture of unit cell.

The actual braided composites which were examined in this study had six layers of braided fibers (see Fig. 2). The axial $\left(0^{\circ}\right)$ fibers in each layer were aligned, but the lateral position of axial fibers in each layer was random. As a result, axial fibers in the various layers are not necessarily located directly over the top of each other, but instead are shifted in a random way relative to the axial fibers in layers above and below. In generating the finite element model for the full six layer composite, this behavior was approximated in an extreme sense for purposes of bounding the problem by shifting each layer of fibers by one subcell to the left in the full model. A schematic of the full finite element model is shown in Figure 2, where subcell A (from the original one layer model) is pink, subcell B is blue, subcell C is green and subcell $\mathrm{D}$ is yellow. The fiber shifting can be observed in this schematic. For example, in the top layer subcell D is the rightmost subcell, in the second layer subcell D is the second from the right subcell, and so forth.

Accounting for the fiber shifting in the subcell model has other advantages for the model as currently formulated. First of all, since in the full model with fiber shifting each subcell has fifteen plies (layers of tows), the overall fiber volume fraction within each subcell is constant. Also, with this fiber layup, each subcell has equal number of $+60^{\circ}$ and $-60^{\circ}$ layers, which makes each subcell quasi-isotropic and representative of the overall composite architecture. Note though that since each subcell has an equal number of $0^{\circ},+60^{\circ}$ and $-60^{\circ}$ fibers, capturing the architecture-dependent damage under impact may be difficult with the six-layer model as currently formulated. In future efforts, modifications to the model to account for this difficulty will be examined. 


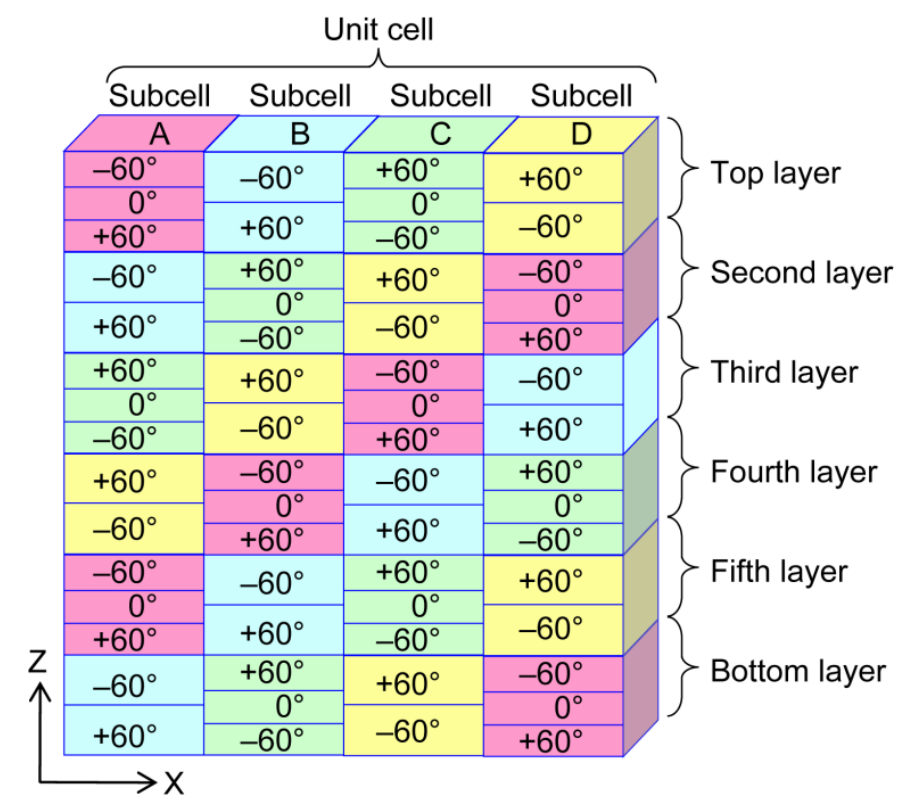

Figure 2.-Schematic of subcell discretization of six-layer triaxial braided composite.

\section{Constitutive Model Overview}

Due to the desire to apply this analysis methodology to the simulation of impact problems, the model was implemented within the context of LS-DYNA (Ref. 9), a commercially available transient dynamic explicit finite element code that is widely used within the aerospace industry to conduct impact analyses. The constitutive model resident within LS-DYNA that was chosen for use with the analysis method is a continuum damage mechanics-based model for unidirectional composites, based on a plane-stress progressive failure theory developed by Matzenmiller, et al. (Ref. 11), that is implemented in LS-DYNA as MAT_58. The failure criterion implemented in the model is based on the Hashin failure criterion. For this material model, the required input stiffness parameters include the unidirectional-ply-level axial and transverse moduli, in-plane shear modulus, and the in-plane Poisson's ratio. The unidirectional-ply-level strength data that is required includes the axial tensile and axial compressive failure stress and failure strain, the transverse tensile and transverse compressive failure stress and failure strain, and the in-plane shear failure stress and failure strain. The stiffness values are used by the material model to simulate the initial linear portion of the composite response. The ply-level strength and ultimate strain values are used to determine the nonlinear portion of the material response and to determine how the damage parameters used as internal variables within the material model evolve over the loading cycle. Furthermore, the user is allowed to specify a "stress limiting factor" in the longitudinal and/or transverse directions. If the value of the "stress limiting factor" is set to zero, the failure stress value is assumed to occur at the specified failure strain, and the material model then "connects the dots" (including enforcing any required material nonlinearity) to create the best-fit stress strain curve that accounts for the specified stiffness and strength values. If the "stress limiting factor" is set to one, the stress-strain curve of the composite is assumed to increase linearly until the maximum strength value is reached. At that point, the material is assumed to act as if it were a perfectly plastic material, with the strain in the specified direction increasing with no increase in stress until such point as the specified strain level is reached, at which point material failure is assumed to occur.

The properties required by the model described above are the properties of the lamina (individual fiber bundles plus a portion of the surrounding resin material). A fundamental problem in the analysis of 
textile composites is that the lamina properties are not known and cannot be directly measured. Attempts can be made to fabricate unidirectional laminates using the same fiber tows that are used to make the preform. This approach is often not easy to accomplish, and the properties of the unidirectional lamina could be different from the properties of the fiber tows within the textile composite because of processing differences. For these reasons, a method was chosen that utilizes an approach based on a combination of classical laminate theory and concepts from composite micromechanics theory to calculate the lamina properties from experimental data obtained on the braided composite. Although there are also some limitations using this approach, the experimental requirements are simplified, and the calculated lamina properties represent the in-situ properties of fiber bundles within the braided composite.

\section{Determination of Material Properties}

The full procedure for the determination of the equivalent unidirectional material properties based on the results of coupon tests on the braided composite is described in detail in Littell, et al (Ref. 10). However, the procedure is summarized below. To back-calculate the stiffness properties, first the geometry of a coupon-level transverse tensile test was considered, where the axial fibers are oriented perpendicular to the applied load and the four subcells of the unit cell are oriented perpendicular to the applied load (see Fig. 2). In addition, the geometry of an axial tensile test was also examined. In this case, the unit cell and subcells were aligned in the direction of the applied load. Mechanics of materials types of assumptions were combined with the assumptions and methods of classical lamination theory to produce a series of equations that relate the applied global stress for the composite coupon (and thus the unit cell) and the subcell-level axial and transverse strains (determined from the experimental data using methods to be described below) to the unidirectional-ply-level stiffness properties. Note that a key assumption in the model development is that only in-plane loads were considered, and in-plane normalshear couplings were neglected.

To apply these equations, the unit cell level stresses and the subcell level strains were assumed to be the known values, and the effective ply-level unidirectional material properties were assumed to be the unknown values. The results from the axial tension and transverse tension tests were applied independently, i.e. stress values from axial tension tests were paired with axial and transverse strain values from axial tension tests, and stress values and axial and transverse strain values from transverse tension tests were linked. To determine the unit cell level stresses, a stress value from the initial linear portion of the stress-strain curve was identified. Full-field strain measurements obtained during axial tension and transverse tension coupon-level tests (see Littell, et al (Ref. 10) for details) were examined to determine the average strain within regions corresponding to specific subcell locations. By utilizing fullfield strain measurements, the overall braid architecture and regions corresponding to specific subcells can be identified. The average strain in each subcell can be measured by tracking points near the edge of each subcell. Strain values from multiple unit cells and subcells were measured and averaged. A visual demonstration of determining the average subcell strains based on optical strain measurements is shown in Figure 3 (Ref. 10). Global stress (and corresponding subcell strain) values were determined from several locations in the linear portion of the axial and transverse stress-strain curves, with their values being applied to the equations. The corresponding computed property values were then averaged to arrive at a single value for each of the unidirectional-ply-level properties. Note that a potential source of error in this procedure is related to the fact that the subcell strains used in the calculations are based on surface strain measurements which may not be totally representative of the average strains through the thickness. These procedures will be modified in future work to account for the fact that in the actual composite the stiffness values for the individual subcells will vary since the fiber volume fraction in each subcell is not constant. 


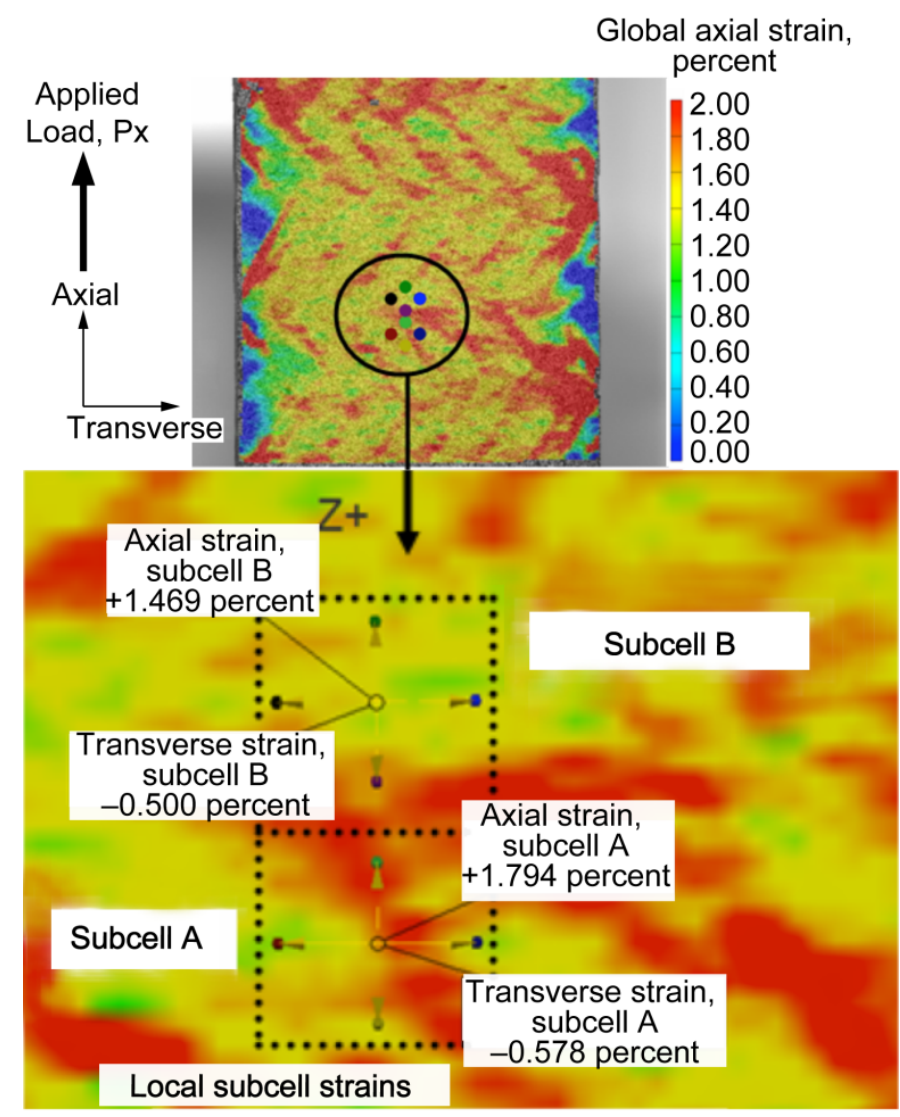

Figure 3.-Optical strain map of local subcell strains used to determine average subcell strains for determination of unidirectional composite stiffness properties.

The unidirectional strength values were also determined from the results of coupon tests on the braided material. The assumption was made that in an axial tensile test the load is primarily carried by the axial fibers, with the bias fibers making relatively small contributions. As a result, the axial failure stress and axial failure strain observed for the braided composite were assumed to be equal to the equivalent ply-level unidirectional-axial failure stress and axial failure strain. The strain field measured during axial compression tests was nearly uniform throughout the gage section with little effect of the braid architecture (see Littell, et al (Ref. 10)). The compressive strains in the axial fibers were therefore assumed to be equal to the global compressive strains in the composite. The compressive stress in the axial fibers was assumed to be equal to the global compressive stress. Therefore, the unidirectional compressive-failure stress and -failure strain were set equal to the measured global compressive-failure stress and -failure strain. To determine the equivalent transverse compressive-failure stress and -failure strain, once again the observation was made that during a transverse compression test, the compressive strains are relatively uniform throughout the gage section, indicating that the compressive strain (and by extension the compressive stress) for the zero degree layers are equal to the compressive stress and strain for the braided composite. Therefore, once again the equivalent unidirectional transverse compressivefailure stress and -failure strain were set equal to the transverse compressive failure stress and failure strain for the braided composite. 

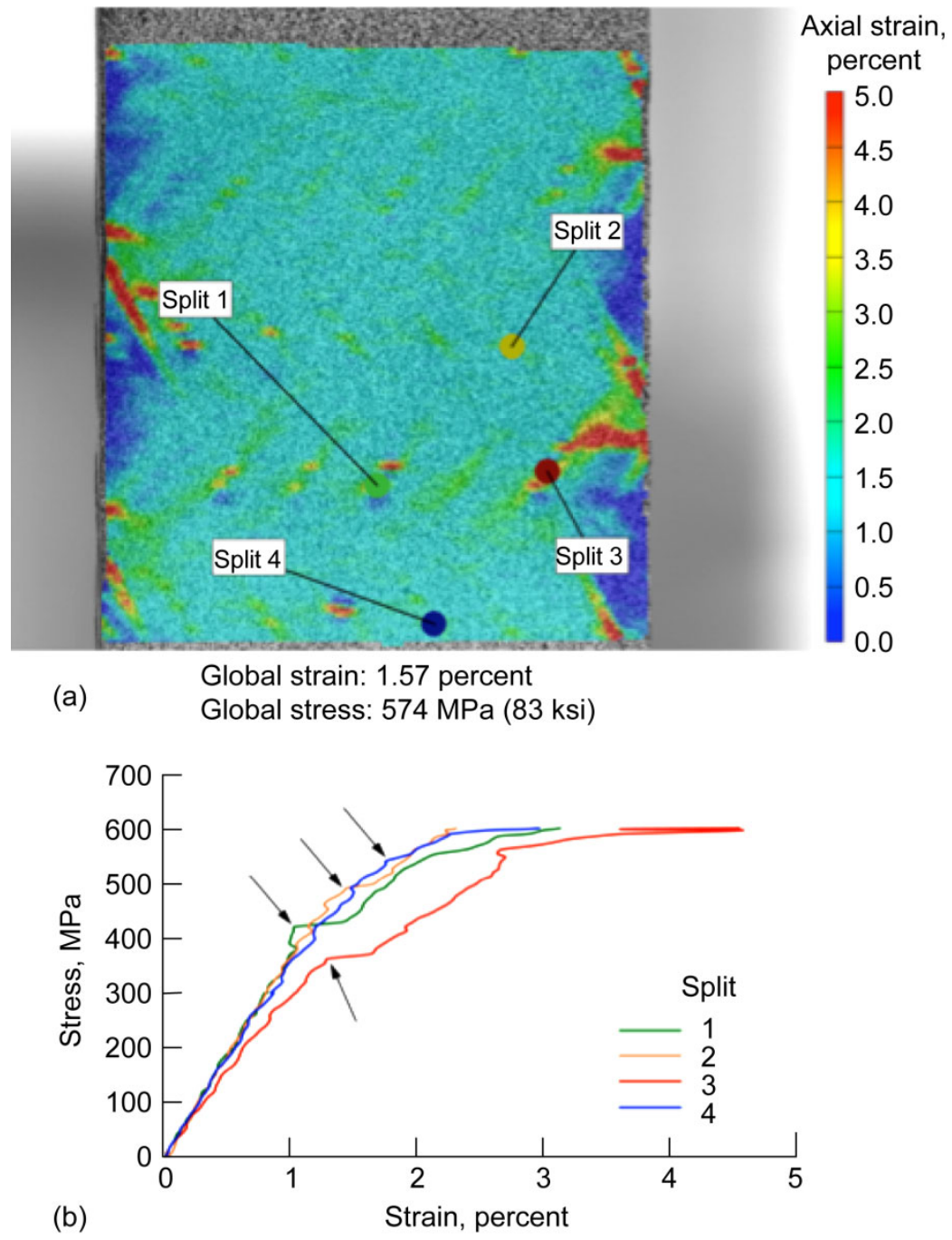

Figure 4.-Transverse tensile test results for T700S/PR520. (a) Full-field strain data. (b) Global stress versus local strain plot.

To determine the equivalent transverse tensile-failure stress of the unidirectional composite, the transverse tensile test data from the braided composites could not be used directly since in a transverse tension test, unlike in an axial tension test, the bias fibers significantly contribute to the global response of the composite. Therefore, full-field strain measurements obtained during transverse tension tests were utilized to obtain the required information. The axial strain field in a transverse tensile specimen (for a T700S/PR520 triaxially-braided composite to be described later in this paper) loaded close to failure is shown in Figure 4(a) (Ref. 10). Global stress versus local strain is shown in Figure 4(b) for the four locations indicated by points in Figure 4(a). Localized damage is visible as small horizontal lines throughout the specimen in Figure 4(a). These local regions of high strain occur as a result of local matrix cracking within the fiber tows, which will hereafter be referred to as "fiber splitting", in the subsurface axial-braid fiber bundles, which lie in a horizontal direction in Figure 4(a). The locations of the first four splits that occur are indicated by colored dots in Figure 4(a). The local strain in the regions of these fiber bundle splits can be measured for each time step in the test. Figure 4(b) shows the global stress versus local strain curves for the four split locations. The curves in Figure 4(b) show an abrupt increase in local strain at the locations indicated by arrows. These abrupt increases are associated with splitting of the 
subsurface axial braid fiber bundles. The global stress at which the abrupt increase in strain occurs can be assumed to approximate the transverse-bundle failure stress. The lowest global transverse stress at which fiber splitting occurred was used as the transverse failure-stress for the unidirectional composite. In a unidirectional composite, complete failure occurs when the transverse failure stress is reached. In a braided composite the fiber bundles are constrained by adjacent fiber bundles, so multiple splits occur within a fiber bundle before complete failure of the composite. To account for this behavior, the "stress limiting factor" in the transverse direction was set equal to one. This allows the material to act as if it were a perfectly plastic material after the onset of fiber bundle splitting. Furthermore, the transversefailure strain for the equivalent unidirectional composite was set equal to the global transverse-failure strain of the braided composite.

To compute the shear-failure stress and the shear-failure strain, the assumption was made that under pure shear loading, the shear stress and shear strain in every layer in all of the subcells was equal to the global-shear stress and -shear strain. Therefore, the equivalent unidirectional shear strength and shear failure strain was assumed to be equal to the shear-failure stress and shear-failure strain measured for the composite.

These approximations will be adjusted in future work to both more accurately account for the fact that each subcell has a different fiber volume fraction (resulting in different strengths in each subcell) and to more accurately relate the global stresses to the actual local stresses present in each composite layer in the analysis model.

\section{Simulation of Quasi-Static Tension Tests}

A series of simulations were conducted to evaluate the analysis methods described above. Specifically, quasi-static axial and transverse coupon-level tensile tests on a T700S/PR520 material were simulated. This material is composed of a two-dimensional triaxial-braided preform and a $177^{\circ} \mathrm{C}$ $\left(350^{\circ} \mathrm{F}\right)$ cure epoxy resin. Specifically, TORAYCA T700S fibers (Toray Carbon Fibers America, Inc.) and a CYCOM PR 520 matrix (Cytec Industries, Inc.) were used. T700S is a high strength, standard modulus carbon fiber. PR520 is a one part toughened resin.

A $\left[0 \%+60^{\circ} /-60^{\circ}\right]$ triaxial-braid architecture was used. The $0^{\circ}$ axial fibers were $24 \mathrm{k}$ flattened tows while the $\pm 60^{\circ}$ bias fibers were $12 \mathrm{k}$ flattened tows. Although larger fiber bundles were used in the axial direction, the fiber bundle spacing in the axial and bias directions were adjusted to give the same fiber volume in the axial and bias directions. This is a nominally quasi-isotropic in-plane fiber architecture, so the global in-plane stiffness is expected to be the same in all directions when the region of interest includes several unit cells of the braid material. Composite panels were fabricated by placing six layers of the braided preform into a mold with the $0^{\circ}$ fibers aligned in the same direction. Although the axial $\left(0^{\circ}\right)$ fibers in the various layers were aligned, the lateral position of the axial tows in the six layers was random. Resin was injected into the closed mold and cured according to processing conditions recommended by the resin manufacturer. The global fiber-volume ratio of the cured composites was measured using the acid digestion technique. The T700S/PR520 composite had a fiber volume of $55.9 \pm 0.18$ percent.

The finite element meshes used in the study are shown in Figure 5. The finite element model for the axial tension test was $20.32 \mathrm{~cm}$ (8.0 in.) long and $3.56 \mathrm{~cm}$ (1.40 in.) wide and had 369 nodes and 320 shell elements. The model for the transverse tensile test was $30.48 \mathrm{~cm}$ (12 in.) long and $3.56 \mathrm{~cm}$ (1.40 in.) wide and had 522 nodes and 476 elements. The fixed end of the model was constrained in all three displacement and rotation directions. The loading was displacement controlled at the rate of $0.0635 \mathrm{~cm} / \mathrm{s}$ ( $0.025 \mathrm{in./s),} \mathrm{which} \mathrm{was} \mathrm{consistent} \mathrm{with} \mathrm{the} \mathrm{test} \mathrm{conditions.} \mathrm{Each} \mathrm{subcell} \mathrm{was} \mathrm{modeled} \mathrm{as} \mathrm{a} \mathrm{layered-shell}$ element, which allows the braid architecture to be explicitly modeled with the finite element mesh of the coupon. In Figure 5, the red elements represent subcell A, the blue elements represent subcell B, the green elements represent subcell $\mathrm{C}$, and the yellow elements represent subcell $\mathrm{D}$. The unit cell orientations for 

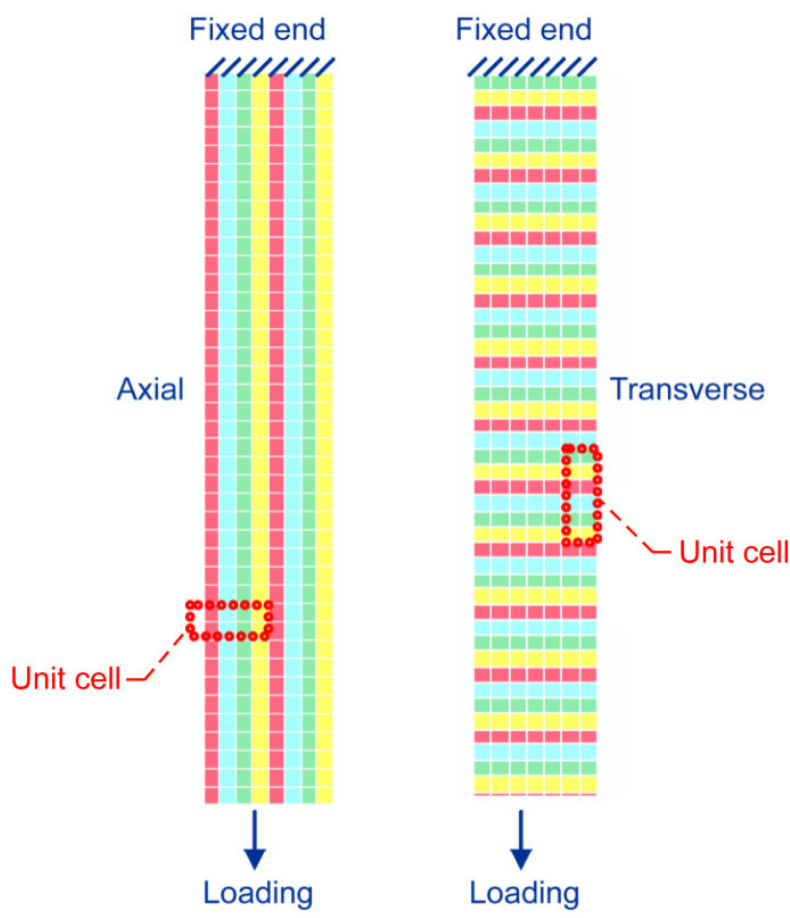

Figure 5.-Finite element models of axial tension (left) and transverse tension (right) tests.

both of the modeling conditions are highlighted in Figure 5 for reference. In the axial test simulation, the unit cell is oriented parallel to the direction of the applied load. In the transverse test simulation, the unit cell is oriented perpendicular to the direction of the applied load. An important point to note is that the analytical techniques developed in this work will ultimately be applied to the analysis of the impact response of braided composites. However, since the experiments that were used to characterize the model were based on quasi-static tests, only these low-rate tests will be simulated in this work. Future efforts will involve using the model to simulate impact events. Furthermore, the capability to account for the strain rate dependent and high strain rate response of the material will be added to the model.

Tensile stress versus strain curves were generated for the T700S/PR520 material in both the axial and transverse directions to examine the correlation of the analysis model to the test data. Even though the coupon level test data was used to obtain the input data applied to the model, due to the complexity of the material model and the ways that the various stiffness and strength parameters interact, the stiffnesses and strengths predicted by the analytical simulations may not necessarily correspond to the parameters determined from the test data. The material properties that were used for the analysis are shown in Table 1. Specimen failure was deemed to occur when all of the elements in a row failed. The element failure occurred nearly simultaneously in the simulations, leading to a fairly abrupt ultimate failure. The resulting stress-strain curves are shown in Figure 6 for the axial tension simulations and Figure 7 for the transverse tension simulations. In these figures and all remaining figures, the test data is as determined by Littell, et al (Ref. 10). 
TABLE 1.-MATERIAL PROPERTY VALUES USED FOR THE QUASI-STATIC COUPON SIMULATIONS

\begin{tabular}{|l|c|}
\hline \multicolumn{1}{|c|}{ Material } & T700 - PR520 \\
\hline Material Parameter Name (LS-DYNA name) & Value (unit) \\
\hline Axial Modulus (EA) & 51.37 (GPa) \\
\hline Transverse Modulus (EB) & 25.03 (GPa) \\
\hline In Plane Shear Modulus (GAB) & 18.96 (GPa) \\
\hline In Plane Poisson Ratio (PRBA) & 0.071 \\
\hline Axial Tensile Failure Strain (E11T) & 0.0216 \\
\hline Axial Compressive Failure Strain (E11C) & 0.018 \\
\hline Transverse Tensile Failure Strain (E22T) & 0.0168 \\
\hline Transverse Compressive Failure Strain (E22C) & 0.011 \\
\hline In Plane Shear Failure Strain (GMS) & 0.024 \\
\hline Axial Tensile Stress at Failure (XT) & $1044.59(\mathrm{MPa})$ \\
\hline Axial Compressive Stress at Failure(XC) & $377.09(\mathrm{MPa})$ \\
\hline Transverse Tensile Stress at Failure (YT) & $361.99(\mathrm{MPa})$ \\
\hline Transverse Compressive Stress at Failure (YC) & $344.75(\mathrm{MPa})$ \\
\hline In Plane Shear Stress at Failure (SC) & $307.31(\mathrm{MPa})$ \\
\hline Stress Limiting Parameter for Axial Tension (SLIMT1) & 0 \\
\hline Stress Limiting Parameter for Transverse Tension (SLIMT2) & 1 \\
\hline Stress Limiting Parameter for Axial Compression (SLIMC1) & 0 \\
\hline Stress Limiting Parameter for Transverse Compression (SLIMC2) & 0 \\
\hline Stress Limiting Parameter for Shear (SLIMS) & 0 \\
\hline
\end{tabular}

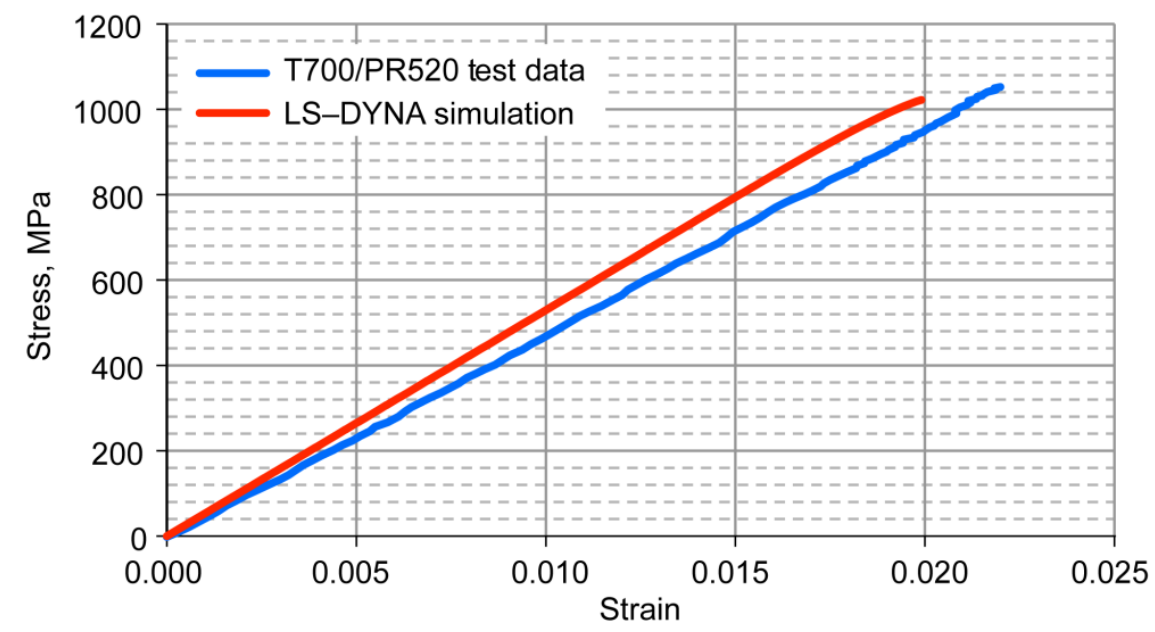

Figure 6.-Test versus simulation for T700 fiber/PR520 resin axial tension material response. 


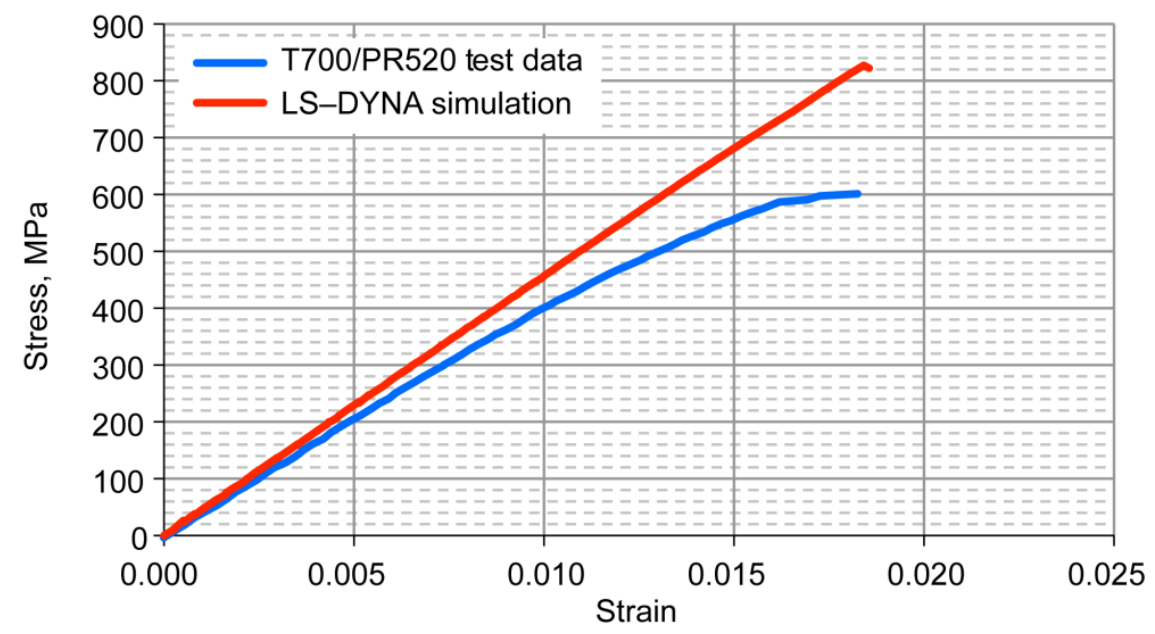

Figure 7.-Test versus simulation for T700 fiber/PR520 resin transverse tension material response.

For the axial tension test, the initial portions of the simulated and experimental curves coincide, but in general the simulated curve is stiffer than the experimental curve. This discrepancy could be due to the fact that in the analysis model every subcell has $0^{\circ}$ layers, which is probably not representative of the actual material architecture, and could lead to the predicted results being overly stiff under axial tension loading (since the $0^{\circ}$ layers promote increased stiffness). Furthermore, results obtained by Littell, et al. (Ref. 10) indicated that in the actual axial tensile tests, fiber splitting occurred in the bias fibers, and there was also some out-of-plane damage, both of which could lead to a weaker response. The current analysis model, due to the shell element formulation, cannot capture any out-of-plane damage. In addition, the presence of the $0^{\circ}$ layers in every subcell of the analysis model could have reduced the influence of any bias fiber damage and weakening in the simulations. However, the fact that the axial tensile specimen exhibited a near linear response until failure was captured in a general sense by the simulations. The simulated axial tensile strength of the specimen also was closely correlated with the experimental results.

The ultimate strength of the transverse tensile specimen was significantly overpredicted, and the simulated response of the transverse tensile test was much more linear than observed in the experiments. A possible cause of the discrepancy in the transverse tensile results can be seen in the full-field strain maps taken from a transverse tensile test which are shown in Figure 4(a). Premature failure near fiber bundles that terminate at free edges can influence the shape of the stress-strain curve and the measured failure strain. A large amount of edge damage was observed in both axial and transverse tensile tests. In an axial tensile test the axial braid fibers lie along the specimen axis and are gripped on both ends during a test. Since these axial braid fibers carry most of the load, the reduction in strength caused by edge damage is small for the axial tensile test. The experimental axial tensile stress-strain curve shown in Figure 6 is therefore nearly linear until failure. The edge damage has a larger effect on the measured strength for the transverse tensile test because all of the axial braid fibers are perpendicular to the applied load. There is no continuous load path between the grips through fibers because all axial and bias fiber bundles terminate at a free edge. The edge damage contributes to the nonlinearity of the experimental transverse tensile stress-strain curve in Figure 7 and also contributes to the reduced transverse failure stress compared with the axial failure stress. The dark blue triangular regions near the edges of the specimen in Figure 4(a) are regions of low strain that are not carrying load because of edge damage. Here, the edge-damaged region is about 10 percent of the specimen width. Since the damaged region does not carry load, the stress in the undamaged region is about 10 percent higher than the stress that is calculated based on the initial cross-sectional area of the specimen. The experimental transverse stress-strain curve in Figure 7 is therefore not an accurate representation of the transverse tensile properties. Due to the nature of the way in which the braid architecture was discretized and simulated in the analytical model, 
with the fiber tows not being modeled in a continuous manner, these local effects could not be captured in the simulations as each subcell in a sense is an independent laminated composite. As a result, the simulated results from the transverse tension test in all likelihood were more representative of the response that would be observed if the response was measured at a location far away from where edge effects would be significant. Therefore, the fact that the transverse tension response of the material was nearly linear, like the axial tension response, with a transverse failure stress only slightly lower than the axial failure stress, is most likely actually more representative of the response of the material as utilized in an engineering structure. Another possible cause of the discrepancy is due to the fact that instead of the elastic-perfectly plastic response in the transverse direction imposed by the material model, the actual material response may be more continuous and generally nonlinear, which could also lead to the experimental results being weaker than the simulated curves. Further studies do need to be made, however, to explore whether the observed discrepancies are caused by limitations in the experimental techniques, limitations imposed by the assumptions used in the analysis method, or both.

\section{Parametric Study of Input Unidirectional Strength Parameters}

To devise ways to modify some of the assumptions that were applied to the original braided through the thickness model (such as the constant fiber volume fraction in each subcell), and to extend the model to account for mechanisms such as material aging and strain rate effects, the need exists to gain a further understanding of the sensitivity of the model predictions to variations in the input data. In particular, due to the complex composite architecture being utilized in the modeling approach (modeling the braid using a series of varying laminated composites), and the complex nature of the constitutive model being utilized, the sensitivity of the model simulations to the various input parameters may not be straightforward. As a result, a study was undertaken where several of the input unidirectional strength parameters were varied independently. The strength parameters were considered to be the most important since these values would most likely to have the most significant effect on the damage and failure of the composite. Repeats of the simulations of the axial tension and transverse tension tests of the braided composite were then conducted to quantify the effects of the parameter variation on the predicted strength of the braided composite.

\section{Six-Layer Model}

For this study, first the unidirectional axial tensile strength (and corresponding axial tensile failure strain) was increased 50 percent and then decreased 50 percent from the baseline values. The baseline "nested" six layer model shown in Figure 2 was analyzed. The results from this study are shown in Figure 8 (composite axial tension simulations) and Figure 9 (composite transverse tension simulations). Next, the unidirectional transverse tensile strength (and corresponding failure strain) was increased 50 percent and then decreased 50 percent. The results from this study are shown in Figure 10 (axial tension simulations) and Figure 11 (transverse tensile simulations). Finally, the in-plane shear strength (and failure strain) was increased 50 percent and decreased 50 percent. The results from this study are shown in Figure 12 (axial tension simulations) and Figure 13 (transverse tension simulations). In these (and several of the following) figures, some stiffening can be seen in several of the simulated curves right before failure occurs. This discrepancy is a numerical artifact resulting from the fact that some instabilities show up in the analysis right before failure occurs. These instabilities are the result of the explicit integration routines used in the finite element solver. Some of the results of the parametric study are intuitive. For example, the fact that varying the unidirectional axial-tensile strength significantly affected the composite axial tensile simulations (Fig. 8) is not surprising since for an axial test the load is primarily carried by the axial fibers. Similarly, the fact that varying the unidirectional transverse-tensile strength did not significantly affect the composite axial tensile response (Fig. 10) is also not surprising since the composite architecture as currently simulated is dominated by the axial fibers (each subcell has a number of $0^{\circ}$ layers), and thus the transverse stresses would not significantly affect the results. 


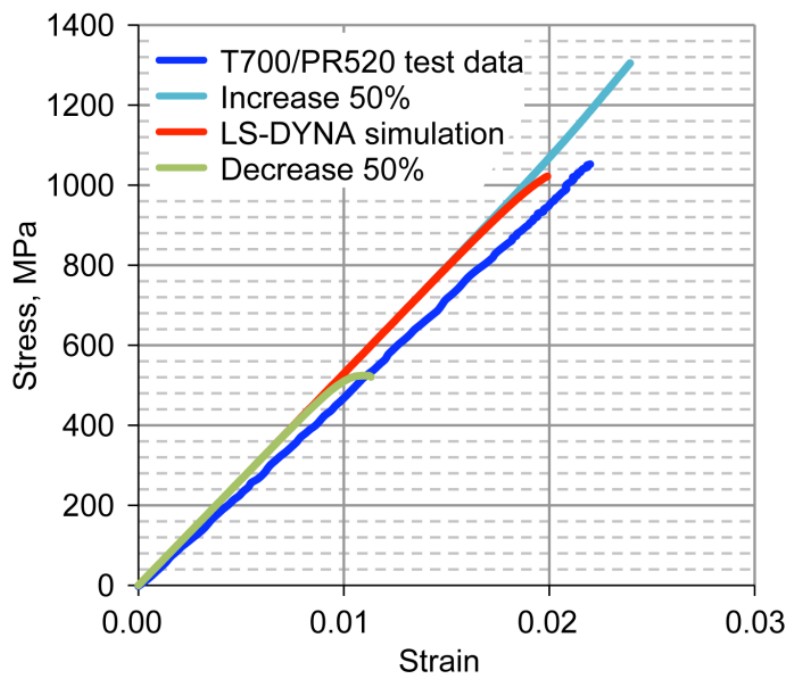

Figure 8.-Effects of varying unidirectional axial tensile strength on T700S/PR520 axial tensile response.

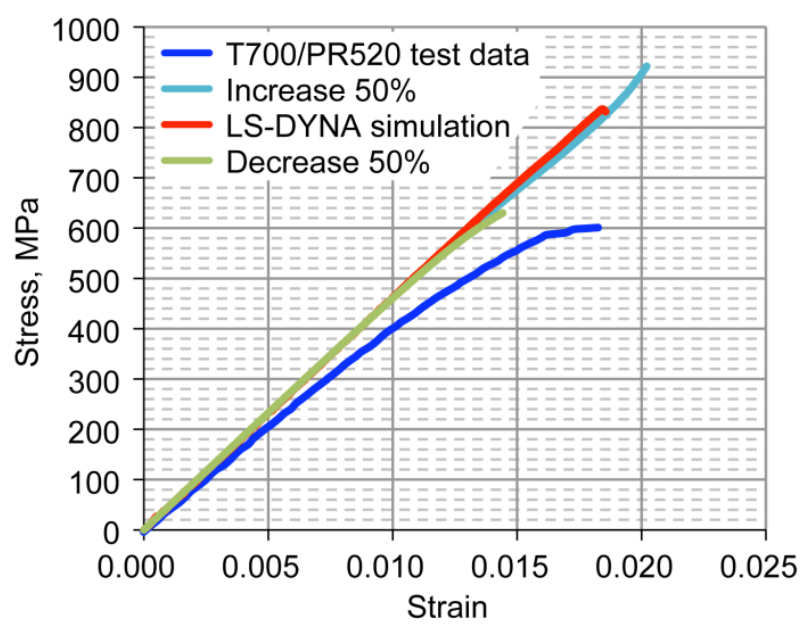

Figure 9.-Effects of varying unidirectional axial tensile strength on T700S/PR520 transverse tensile response.

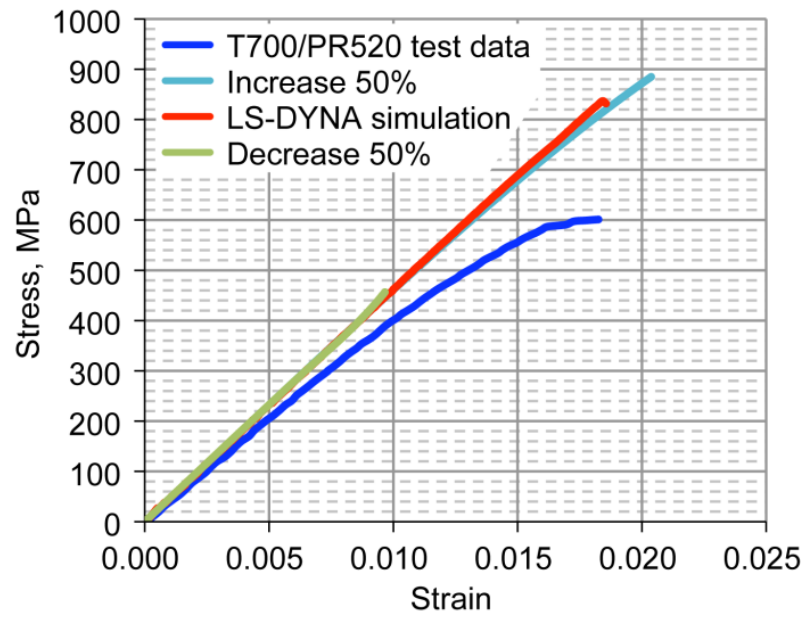

Figure 11.-Effects of varying unidirectional transverse tensile strength on T700S/PR520 transverse tensile response.

Figure 10.-Effects of varying unidirectional transverse tensile strength on T700S/PR520 axial tensile response. 


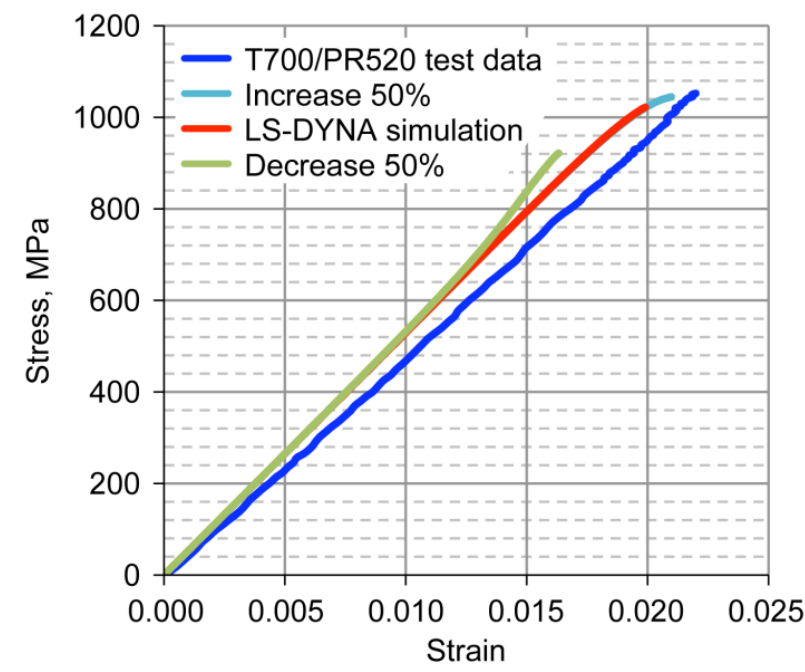

Figure 12.-Effects of varying unidirectional in-plane shear strength on T700S/PR520 axial tensile response.

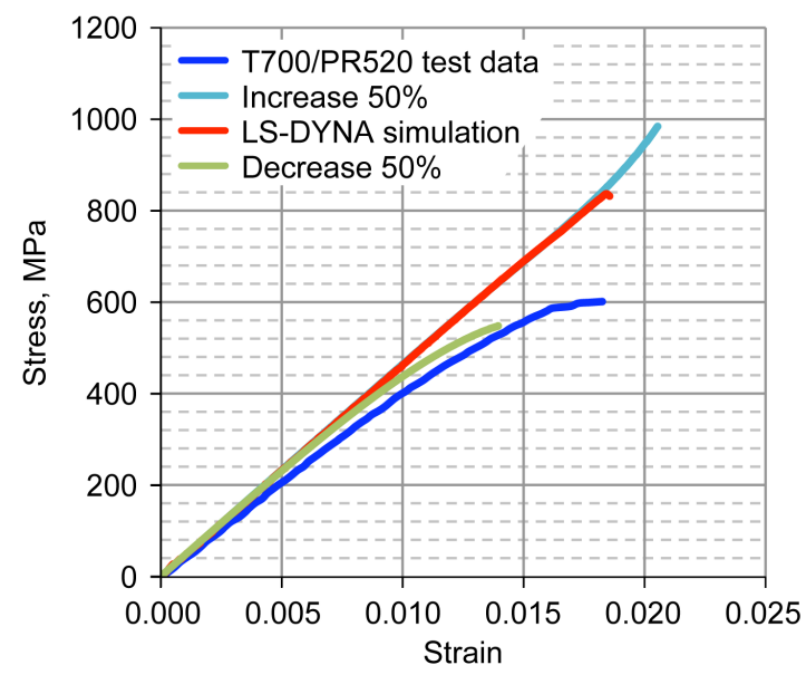

Figure 13.-Effects of varying unidirectional in-plane shear strength on T700S/PR520 transverse tensile response.

Furthermore, as seen in Figure 13, varying the unidirectional in-plane shear strength significantly affected the predicted composite transverse-tensile strength. These results were expected since the stresses in the matrix are dominant under transverse tensile loading, and the in-plane shear strength is primarily driven by the stresses in the matrix.

However, some of the results obtained from the parametric study were not as intuitive. For example, as seen in Figure 9, decreasing the uniaxial axial-tensile strength significantly lowered the predicted composite transverse-tensile strength. This result is counterintuitive since one would not expect the longitudinal stresses to play a key role in a transverse tension test. However, these results indicate that the bias fibers might be failing in an axial manner. Likewise, as is seen in Figure 11, while decreasing the unidirectional transverse-tensile strength resulted in a lower predicted composite transverse-tensile strength, which would be expected (due to the fact that both are driven by matrix stresses), increasing the unidirectional transverse-tensile strength resulted in a minimal increase in the predicted composite transverse strength, which is somewhat unexpected. Furthermore, as seen in Figure 12 reducing the unidirectional in-plane shear strength resulted in a reduction in the predicted composite axial-tensile strength, which is somewhat unexpected since the composite axial tensile strength should primarily be driven by the axial tensile strength of the longitudinal fibers (layers). The exact reasons for these discrepancies are currently unclear and are under further investigation. However, the causes of these results are most likely due to the fact that the equations predicting the initiation and propagation of damage within the material constitutive model are based on interactive combinations of the stresses and strengths, resulting in fairly smooth damage and failure surfaces. Particularly in the bias $\left( \pm 60^{\circ}\right)$ fibers, the stress state is highly multiaxial, which when combined with the damage and failure criteria most likely leads to nonintuitive results.

\section{Single-Layer Model}

To further explore the effects of varying the input strength parameters, a revised model composed of only one layer of the braided material, similar to that shown in Figure 1(c), was analyzed. By examining the single layer model, some of the complexity of the six layer model is removed, which allows for a simpler analysis of the effects of the input strength parameters. Furthermore, to eventually model the impact damage observed in actual structures, an analysis model with different fiber layups in each subcell will be required in order to capture the architecturally-dependent damage. However, by shifting to this revised analysis model, the approximation made for the six-layer model that the fiber volume ratio is the same in all subcells is no longer valid. The fiber volume ratio in subcells A and C should now be greater 
than the fiber volume ratio in subcells B and D, with corresponding changes in the material properties. Future efforts will concentrate on properly modifying the material property input to reflect this situation. However, for this study, the same material properties used for the baseline study will be applied, with the understanding that the quantitative comparison of the analysis results to the experimental values (particularly in the axial tension simulations) will not be as good. However, the qualitative examination of the effects of the input parameters on the computed results should still be valid. Another difference between the six-layer model and the single layer model is that in the six-layer model the layer thickness in all of the subcells was equal. In the single-layer model, due to the fact that subcells A and $C$ have 3 layers and subcells B and D have two layers, the layer thicknesses in subcells B and D are larger than those in subcells A and C. The overall layout for the finite element model is the same as was shown in Figure 5.

To explore the effects of using the single-layer model (as compared to the "nested" six-layer model), the axial tension test described earlier was simulated using the single-layer model with the results shown in Figure 14. The transverse tensile test was also simulated with the results shown in Figure 15. As can be seen in the figures, the single layer simulations were softer, particularly in the nonlinear region, as compared to the six layer simulations. The results were more pronounced with the axial tension simulations. To provide a better "apples to apples" comparison between the two analysis models, a sixlayer "unnested" model was created by stacking six layers of the single-layer model to create a modified six-layer model, as shown schematically in Figure 16. The results computed using this six-layer "unnested" model are shown in Figure 17 for the axial tension simulation and in Figure 18 for the transverse tension simulation. As can be seen in Figure 17, the computed results under axial tension conditions for the single layer and "unnested" six-layer model were very close, with the "unnested" six layer model having a slightly higher final strength. As seen in Figure 18, using the "unnested" six-layer model under transverse tension conditions resulted in a slightly stiffer material response as compared to the single-layer model, to the point where the results obtained using the "unnested" six-layer model very closely tracked the results from the original "nested" six-layer model, with the only major difference being that the "unnested" six-layer model had a somewhat lower final strength as compared to the "nested" model. Even though the results obtained using the single layer model are closer to the experimental results than the results obtained using either of the six-layer models, given the deficiencies identified in the transverse tension tests and the approximations in the analysis method (which as discussed above indicate that the results obtained using the "nested" six-layer model may be closer to reality), the fact that the "unnested" six layer results tracked closer to the "nested" six layer results may indicate that the "unnested" six layer model yields more accurate results that the single-layer model.

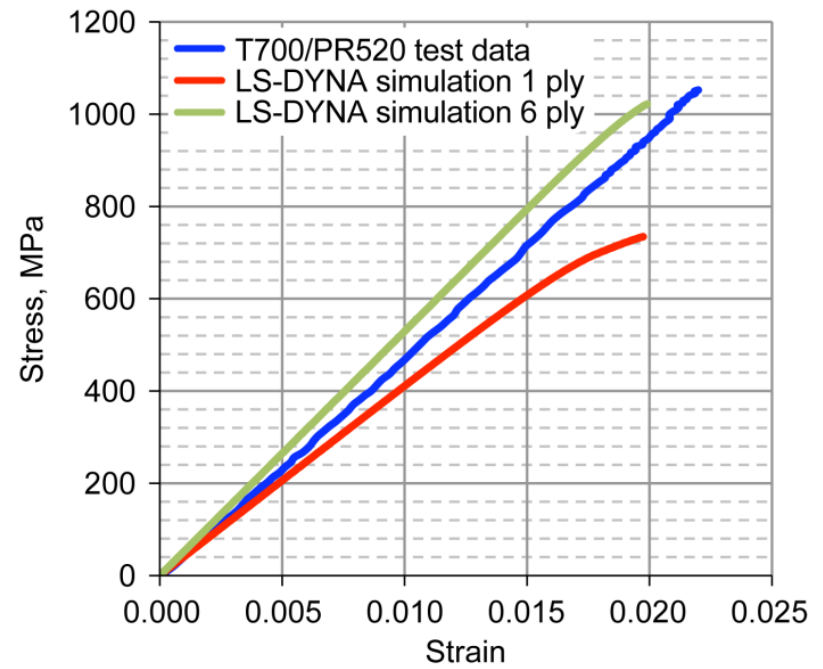

Figure 14.-Axial tensile response of T700S/PR520 composite using single layer analysis model.

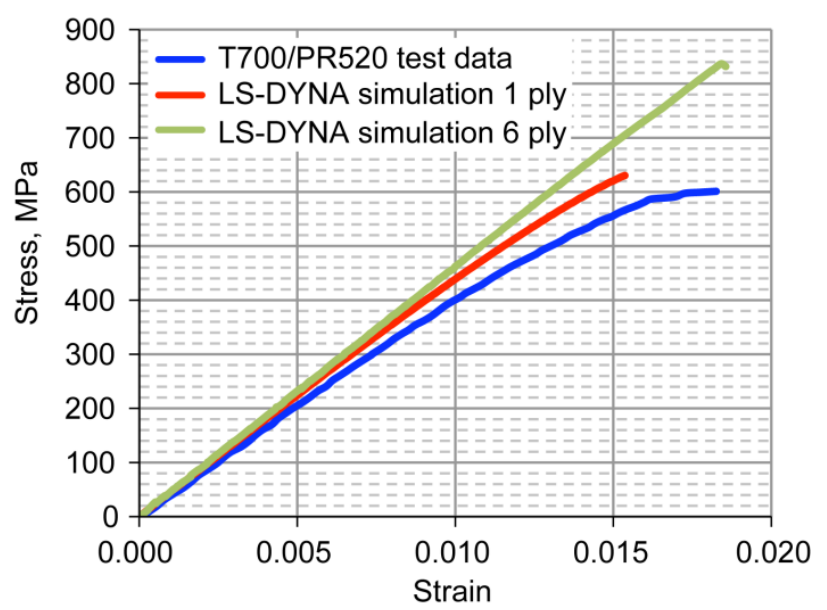

Figure 15.-Transverse tensile response of T700S/PR520 composite using single layer analysis model. 


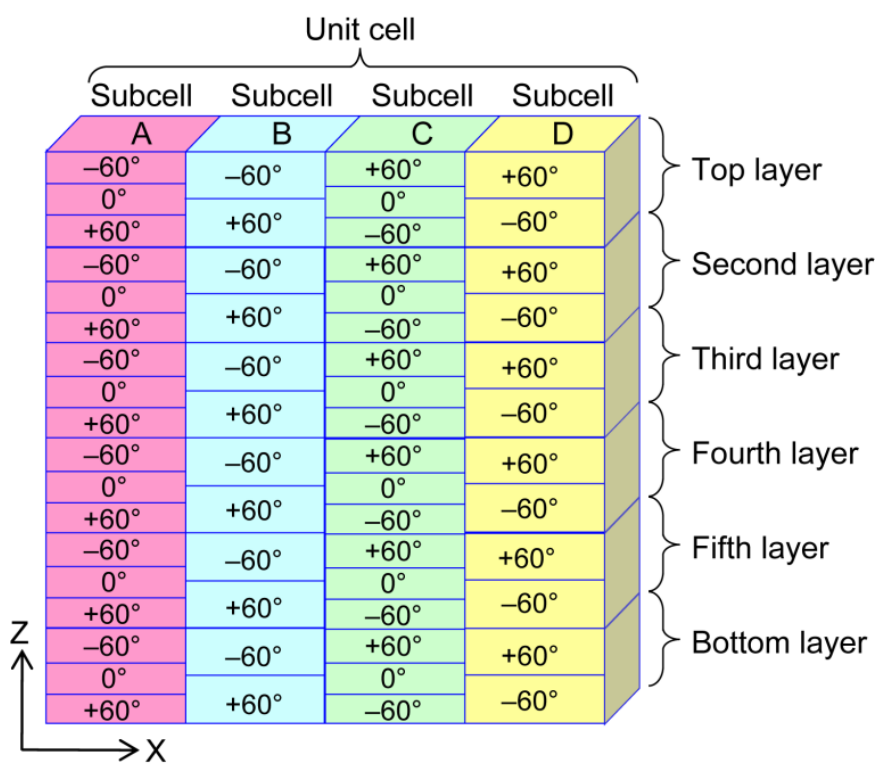

Figure 16.-Schematic of subcell discretization of "unnested" six layer triaxial braided composite.

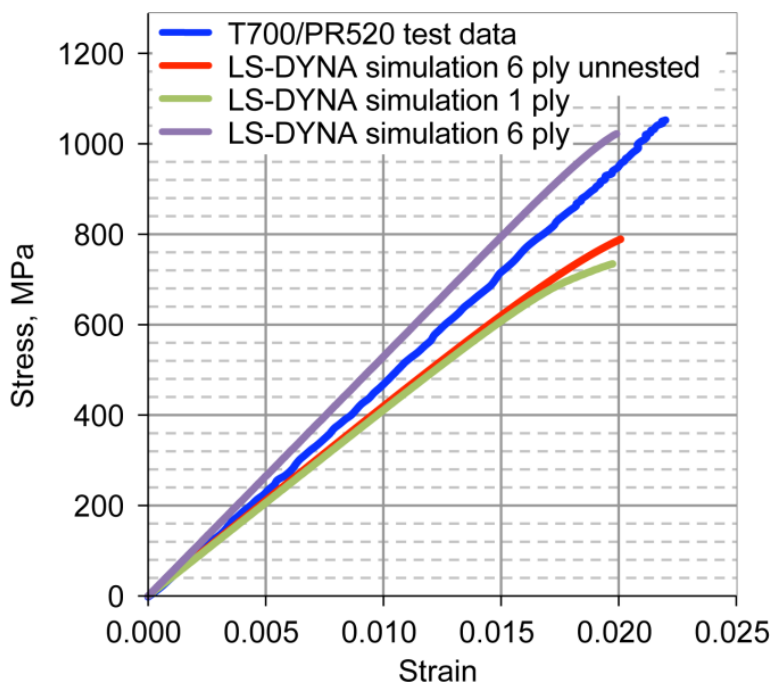

Figure 17.-Axial tensile simulations of T700S/PR520 composite using "nested" six layer, single layer and "unnested" six layer analysis models.

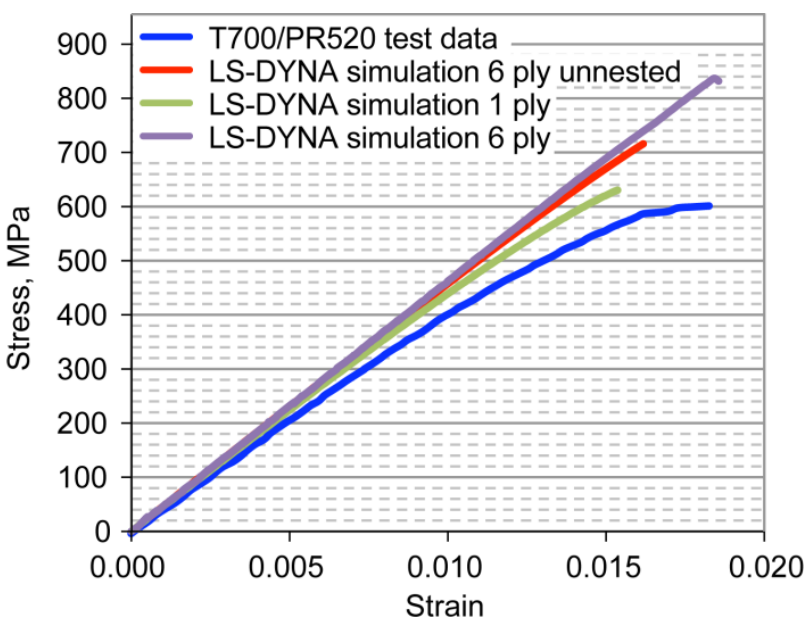

Figure 18.-Transverse tensile simulations of T700S/ PR520 composite using "nested" six layer, single layer and "unnested" six layer analysis models.

To examine the reasons for the differences between the "nested" six-layer and the single-layer (and by extension the "unnested" six layer) models in more detail, the stress-strain response for subcells A and C and subcells B and D were individually computed, with the results shown in Figure 19 for the axial tension case and Figure 20 for the transverse tension case. In each of these figures, the curves labeled "LS-DYNA Simulation 1 ply" and "LS-DYNA simulation 6 ply" are the overall, effective stress-strain curves for the composite for the single layer and "nested" six layer cases, respectively. The curves labeled "Simulation 1 ply AC" are the results specifically for subcells A and C from the single layer analysis and the curves labeled "Simulation 1 ply BD" are the results specifically for subcells B and D from the single 
layer analysis. As can be seen in Figure 19, for the axial tension case, the results for subcells A and C almost identically track the results from the six-layer "nested" model. These results are reasonable since subcells A and C and the "nested" six-layer model both have a mixture of $0^{\circ},+60^{\circ}$ and $-60^{\circ}$ layers. Conversely, the results for subcells B and D are much softer, reflecting the fact that these subcells do not have any $0^{\circ}$ layers, which in an axial tension test provide the majority of the stiffness. The average of the two subcell sets then would result in the overall, relatively softer material response in the case of the single layer simulations. The fact that the response for subcells B and D flattens out indicates that the local transverse stresses have reached the transverse-failure stress for the single ply simulations. In examining the transverse tension results in Figure 20, the results for each of the subcells tracked along the same path as the average results for the full single-layer model. However, the results for subcells A and C had a final predicted strength near to that of the "nested" six-layer model, and the results for subcells B and D had a predicted strength that was significantly lower, leading to the average curve for the single layer simulations that has a strength that is lower than the "nested" six-layer results. If the same study was conducted using the "unnested" six layer model, based on the case shown in Figure 18, the results for subcells A and C would most likely track very closely to the results for the "nested" six-layer model. Hence, the axial $0^{\circ}$ layers do not significantly contribute to the overall transverse stiffness, which is reasonable, but they do cause an increase in the transverse strength.

The parametric study that was conducted for the "nested" six-layer model was repeated for the singlelayer model. First the unidirectional axial-tensile strength (and corresponding axial-tensile failure strain) was increased 50 percent and then decreased 50 percent from the baseline values. The results from this study are shown in Figure 21 (composite axial-tension simulations) and Figure 22 (composite transversetension simulations). Next, the unidirectional transverse-tensile strength (and corresponding failure strain) was increased 50 percent and then decreased 50 percent. The results from this study are shown in Figure 23 (axial tension simulations) and Figure 24 (transverse tensile simulations). Finally, the in-plane shear strength (and failure strain) was increased 50 percent and decreased 50 percent. The results from this study are shown in Figure 25 (axial tension simulations) and Figure 26 (transverse tension simulations).

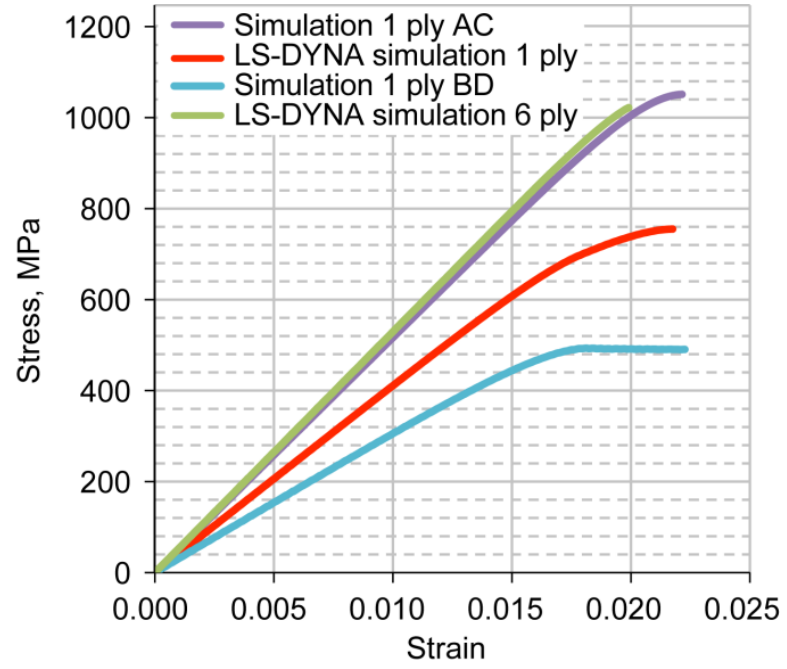

Figure 19.--Response of individual subcells in axial tensile simulation of T700S/PR520 composite using single layer analysis model.

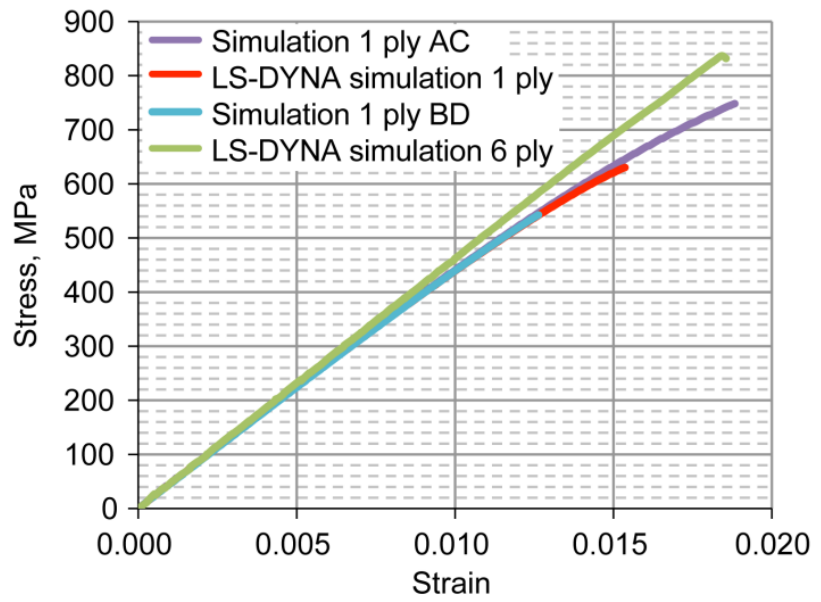

Figure 20.-Response of individual subcells in transverse tensile simulation of T700S/PR520 composite using single layer analysis model. 


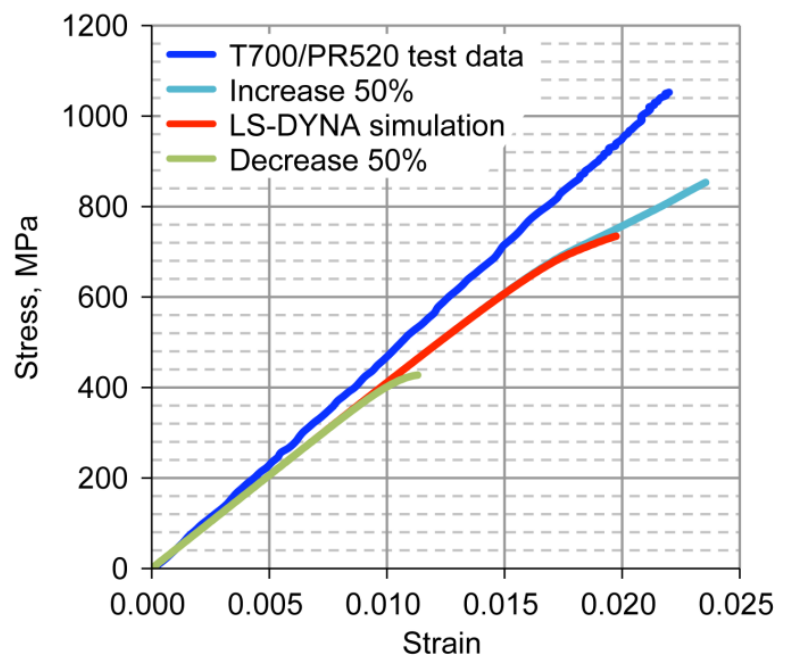

Figure 21.-Effects of varying unidirectional axial tensile strength on T700S/PR520 axial tensile response using single layer analysis model.

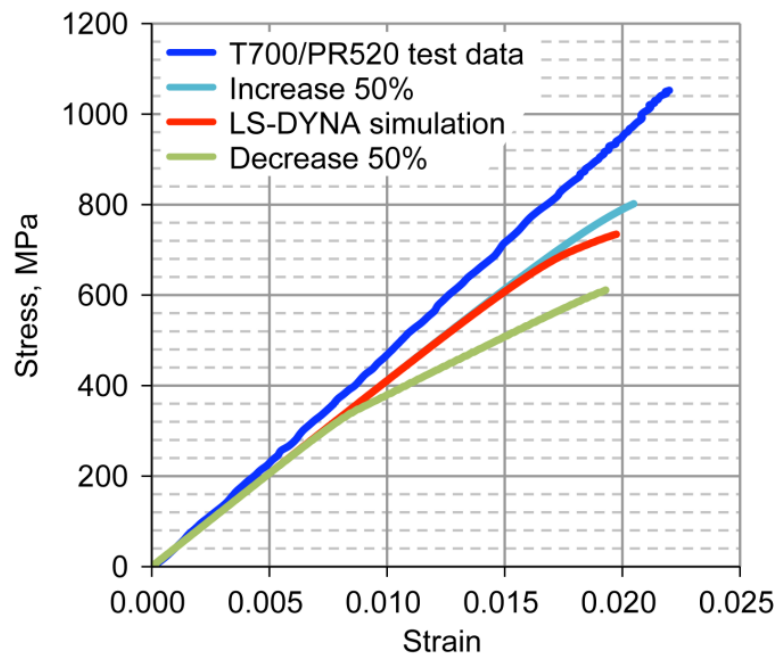

Figure 23.-Effects of varying unidirectional transverse tensile strength on T700S/PR520 axial tensile response using single layer analysis model.

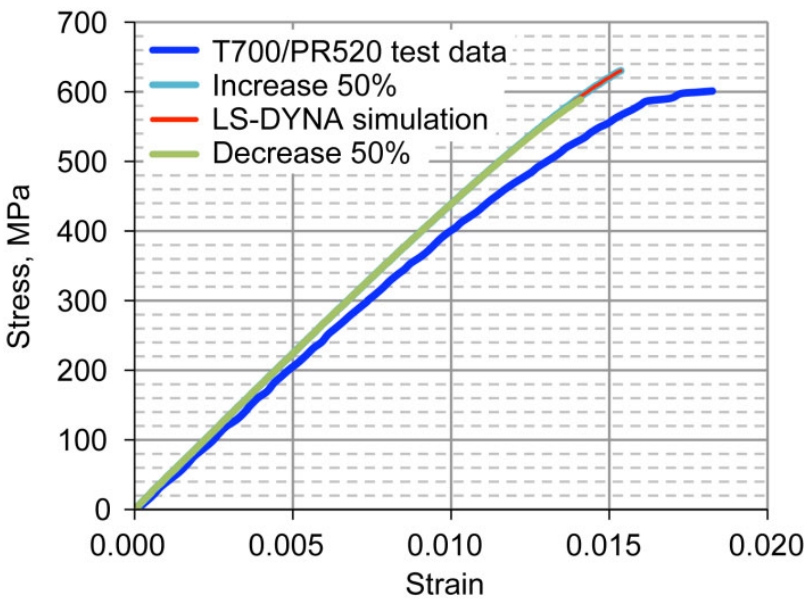

Figure 22.-Effects of varying unidirectional axial tensile strength on T700S/PR520 transverse tensile response using single layer analysis model.

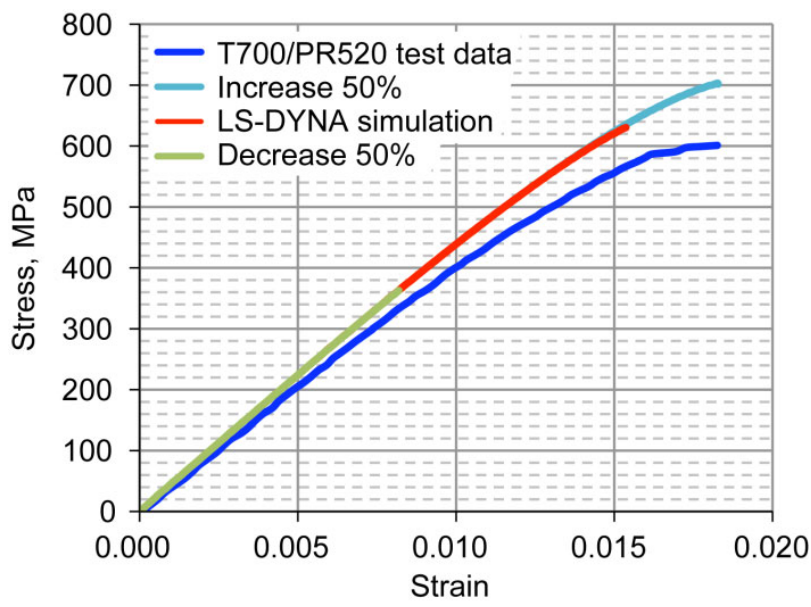

Figure 24.-Effects of varying unidirectional transverse tensile strength on T700S/PR520 transverse tensile response using single layer analysis model. 


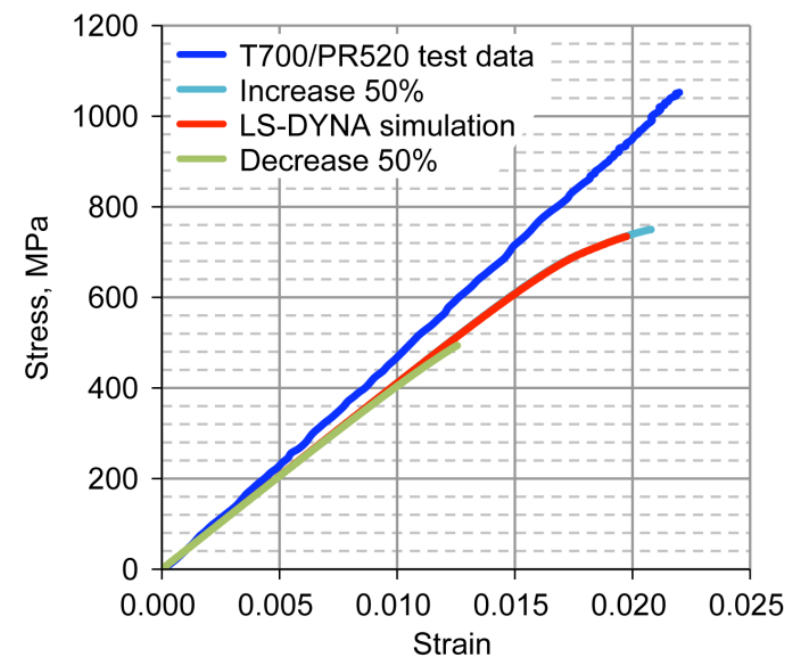

Figure 25.-Effects of varying unidirectional in-plane shear strength on T700S/PR520 axial tensile response using single layer analysis model.

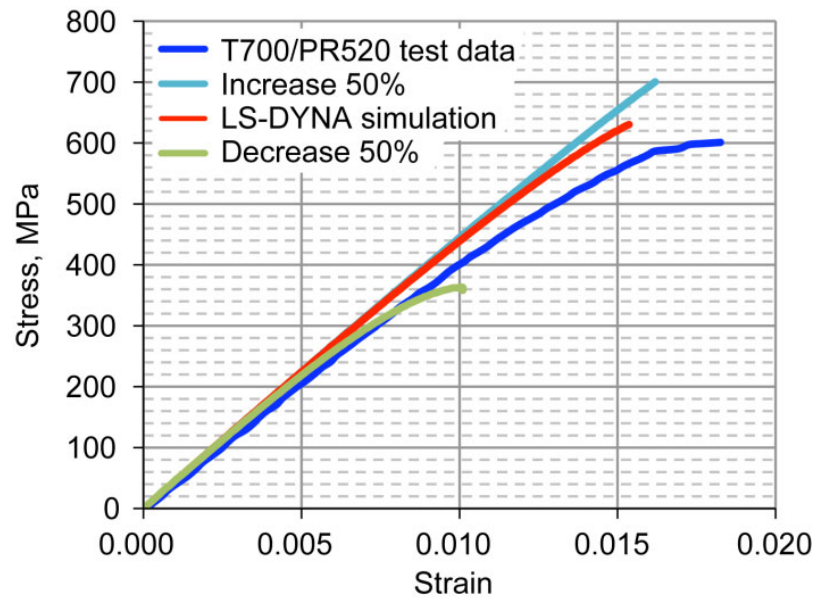

Figure 26.-Effects of varying unidirectional in-plane shear strength on T700S/PR520 transverse tensile response using single layer analysis model.

As can be seen in Figures 21 and 22, varying the unidirectional axial-tensile strength resulted in significant changes in the composite axial-tensile response but minimal changes in the composite transverse-tensile response. These results are both intuitive based on the fiber architecture, as the unidirectional axial-tensile strength should primarily effect the composite axial-tensile response. The reason that in the "nested" six-layer model the unidirectional axial-tensile strength affected the composite transverse-tensile response is still unclear.

Examining the effects of varying the unidirectional transverse-tensile strength in Figures 23 and 24, varying the transverse strength affected both the composite axial-tension and transverse-tension response. While the fact that varying the unidirectional transverse-tensile strength would significantly affect the composite transverse tensile response is fairly intuitive (since the loading in all of the layers is primarily a transverse load), the fact that varying the unidirectional transverse-tensile strength would affect the composite axial-tensile response is not intuitive. However, the reason for this variation can be seen in Figure 27, where the effect of varying the unidirectional transverse-tensile strength on the response of the individual subcells is shown for the axial-tension simulations. As can be seen in Figure 27, changing the unidirectional transverse-tensile strength resulted in no change in the response of subcells $\mathrm{A}$ and $\mathrm{C}$, which would be expected due to the axial response of the $0^{\circ}$ layers driving this response. This also most likely explains why for the "nested" six-layer model changing the unidirectional transverse-tensile strength did not affect the composite axial-tensile response. However, changing the unidirectional transverse-tensile strength significantly affected the axial response of subcells B and D. Specifically, the response of subcells B and D became much more linear as the transverse strength was increased, and the response of the two subcells became nonlinear at a much lower stress as the transverse strength was reduced. This result is actually reasonable since even under an axial tensile load the bias fibers are under a multiaxial stress state, and the interaction between the stresses could be significant enough to affect how the constitutive model simulates the material behavior. In particular, these results indicate that by raising the transverse strength, the local transverse stresses now stayed below the transverse failure strength. Furthermore, reducing the transverse strength caused the transverse stresses in the subcells to reach the revised, lower transverse strength at a relatively low strain. These results were reflected in the overall average composite curve, as raising the unidirectional transverse-failure stress caused the overall curve to become more linear, and reducing the transverse-failure stress caused the overall curve to become more nonlinear. 


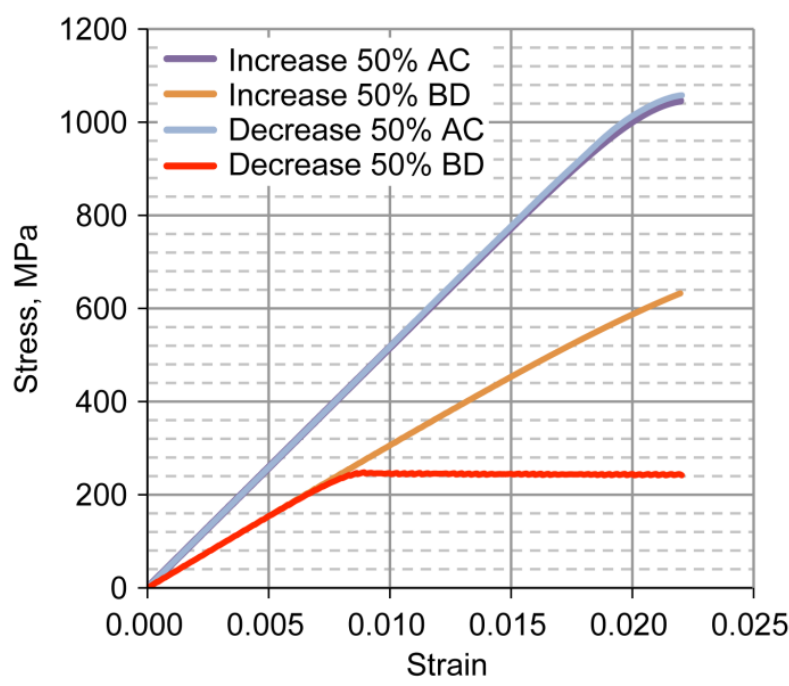

Figure 27.-Effects of varying unidirectional transverse tensile strength on response of individual subcells for axial tensile simulation of T700S/PR520 composite using single layer analysis model.

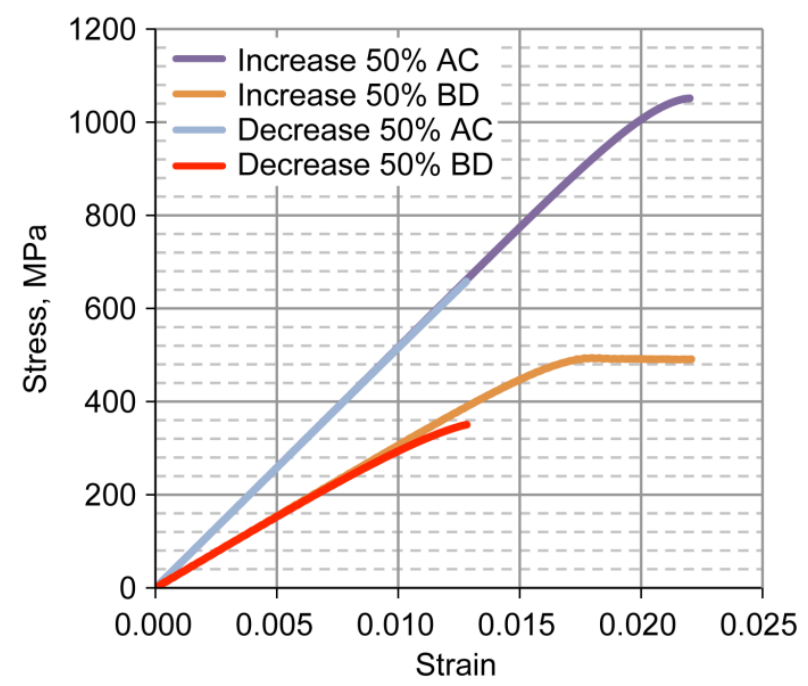

Figure 28.-Effects of varying unidirectional in-plane shear strength on response of individual subcells for axial tensile simulation of T700S/PR520 composite using single layer analysis model.

Examining the effects of varying the unidirectional in-plane shear strength in Figures 25 and 26, for both the composite axial tension and transverse tension cases varying the in-plane shear strength once again affected both the composite axial-tension and transverse-tension responses. As for the case of the transverse-tensile strength, the fact that changing the unidirectional in-plane shear strength would affect the composite transverse-tensile response is fairly intuitive, but the fact that lowering the in-plane shear strength would affect the axial-tensile response is once again not necessarily what would be expected. By examining the individual subcell responses for the axial tensile simulations in Figure 28, however, the results make sense. As can be seen in this figure, lowering the unidirectional in-plane shear strength caused the failure stress of all the subcells to be significantly reduced for the case of axial tensile loading. These results indicate that for the multiaxial stress state that results in the bias fibers in all of the subcells, the local shear stresses must reach the reduced shear strength, resulting in relatively early failure.

\section{Conclusions}

A macro-level finite element-based approach has been developed which allows for the simulation of the response of a triaxially-braided composite in a manner which takes into account the architecture of the braided material within a structure. The input material properties utilized for the analysis can be determined based on experimental tests conducted on the braided composite. The analysis model, which utilizes LS-DYNA shell elements, appears promising in its ability to simulate the axial and transverse deformation and failure of the braided material. The various material strength parameters that are input to the model have a significant effect on the overall results of the simulations, sometimes in ways that at first glance appear to be non-intuitive. However, detailed studies of the material response indicated that many of what appeared to be non-intuitive effects could be explained and made sense within the context of the analysis model. Future efforts will involve modifying the analysis model to allow for each of the subcells in the discretization to have different fiber-volume ratios, and thus different material properties, which is more representative of the actual composite. Furthermore, the analysis model will be adapted to permit the analysis of the strain rate-dependent response of the braided-polymer composites. In particular, simulations of impact events will be conducted. Methods to utilize the model to explore composite materials subject to aging, or materials with weak fiber-matrix interfaces or brittle matrices will also be explored. 


\section{References}

1. Chou, T.W. and Ishikawa, T.: "Analysis and Modeling of Two-Dimensional Fabric Composites," in Textile Structural Composites, Composite Material Series, Vol. 3, T.W. Chou and F.K. Ko, Eds., Elsevier Science Publishers B.V., Amsterdam, 1989, Ch. 7, pp. 209-277.

2. Naik, N.K.; and Shembedkar, P.S.: "Elastic Behavior of Woven Fabric Composites: I-Lamina Analysis,” Journal of Composite Materials, Vol. 26, No. 15, pp. 2196-2225, 1992.

3. Pastore, C.M. and Gowayed, Y.A.: "A Self-Consistent Fabric Geometry Model: Modifications and Application of a Fabric Geometry Model to Predict the Elastic properties of Textile Composites," Journal of Composites Technology and Research, Vol. 16, No. 1, pp. 32-36, 1994.

4. Byun, J.-H.: "The analytical characterization of 2-D braided textile composites,” Composites Science and Technology, Vol. 60, No. 5, pp. 705-716. 2000.

5. Tanov, R. and Tabiei, A.: "Computationally Efficient Micromechanical Models for Woven Fabric Composite Elastic Moduli,” Journal of Applied Mechanics, Vol. 68, No. 4, pp. 553-560, 2001.

6. Bednarcyk, B.A.; and Arnold, S.M.: "Micromechanics-Based Modeling of Woven Polymer Matrix Composites,” AIAA Journal, Vol. 41, No. 9, 2003.

7. Roberts, G.D. et al. "Impact Testing and Analysis of Composites for Aircraft Engine Fan Cases," NASA/TM-2002-211493, 2002.

8. Cheng, Jingyun. Material Modeling of Strain Rate Dependent Polymer and 2D Triaxially Braided Composites. Ph.D. Dissertation. University of Akron. Akron, Ohio. 2006.

9. Livermore Software Technology Corporation. LS-DYNA Keyword Manual v 971. Livermore, CA, 2007.

10. Littell, J.D.; Binienda, W.K.; Goldberg, R.K.; and Roberts, G.D.: “A Modeling Technique and Representation of Failure in the Analysis of Triaxial Braided Carbon Fiber Composites," NASA/TM-2008-215245, 2008.

11. Matzenmiller, A.; Lubliner, J.; and Taylor, R.L.: “A Constitutive Model for Anisotropic Damage in Fiber-Composites,” Mechanics of Materials 20, pp. 125-152, 1995. 


\begin{tabular}{|c|c|c|}
\hline \multicolumn{2}{|c|}{ REPORT DOCUMENTATION PAGE } & $\begin{array}{l}\text { Form Approved } \\
\text { OMB No. 0704-0188 }\end{array}$ \\
\hline \multicolumn{3}{|c|}{$\begin{array}{l}\text { The public reporting burden for this collection of information is estimated to average } 1 \text { hour per response, including the time for reviewing instructions, searching existing data sources, gathering and maintaining the } \\
\text { data needed, and completing and reviewing the collection of information. Send comments regarding this burden estimate or any other aspect of this collection of information, including suggestions for reducing this } \\
\text { burden, to Department of Defense, Washington Headquarters Services, Directorate for Information Operations and Reports (0704-0188), 1215 Jefferson Davis Highway, Suite } 1204 \text {, Arlington, VA } 22202-4302 \text {. } \\
\text { Respondents should be aware that notwithstanding any other provision of law, no person shall be subject to any penalty for failing to comply with a collection of information if it does not display a currently valid OMB } \\
\text { control number. } \\
\text { PLEASE DO NOT RETURN YOUR FORM TO THE ABOVE ADDRESS. }\end{array}$} \\
\hline $\begin{array}{l}\text { 1. REPORT DATE (DD-MM-YYYY) } \\
01-07-2010\end{array}$ & $\begin{array}{l}\text { 2. REPORT TYPE } \\
\text { Technical Memorandum }\end{array}$ & 3. DATES COVERED (From - To) \\
\hline \multirow{3}{*}{\multicolumn{2}{|c|}{$\begin{array}{l}\text { 4. TITLE AND SUBTITLE } \\
\text { Investigation of a Macromechanical Approach to Analyzing Triaxia } \\
\text { Composites }\end{array}$}} & 5a. CONTRACT NUMBER \\
\hline & & 5b. GRANT NUMBER \\
\hline & & 5c. PROGRAM ELEMENT NUMBER \\
\hline \multirow{3}{*}{\multicolumn{2}{|c|}{$\begin{array}{l}\text { 6. AUTHOR(S) } \\
\text { Goldberg, Robert, K.; Blinzler, Brina, J.; Binienda, Wieslaw, K. }\end{array}$}} & 5d. PROJECT NUMBER \\
\hline & & 5e. TASK NUMBER \\
\hline & & $\begin{array}{l}\text { 5f. WORK UNIT NUMBER } \\
\text { WBS 698259.02.07.03.03.01 }\end{array}$ \\
\hline \multicolumn{2}{|c|}{$\begin{array}{l}\text { 7. PERFORMING ORGANIZATION NAME(S) AND ADDRESS(ES) } \\
\text { National Aeronautics and Space Administration } \\
\text { John H. Glenn Research Center at Lewis Field } \\
\text { Cleveland, Ohio 44135-3191 }\end{array}$} & $\begin{array}{l}\text { 8. PERFORMING ORGANIZATION } \\
\text { REPORT NUMBER } \\
\text { E-17307 }\end{array}$ \\
\hline \multirow{2}{*}{\multicolumn{2}{|c|}{$\begin{array}{l}\text { 9. SPONSORING/MONITORING AGENCY NAME(S) AND ADDRESS(ES) } \\
\text { National Aeronautics and Space Administration } \\
\text { Washington, DC 20546-0001 }\end{array}$}} & $\begin{array}{l}\text { 10. SPONSORING/MONITOR'S } \\
\text { ACRONYM(S) } \\
\text { NASA }\end{array}$ \\
\hline & & $\begin{array}{l}\text { 11. SPONSORING/MONITORING } \\
\text { REPORT NUMBER } \\
\text { NASA/TM-2010-216371 }\end{array}$ \\
\hline \multicolumn{3}{|c|}{$\begin{array}{l}\text { 12. DISTRIBUTIONIAVAILABILITY STATEMENT } \\
\text { Unclassified-Unlimited } \\
\text { Subject Categories: } 24 \text { and } 39 \\
\text { Available electronically at http://gltrs.grc.nasa.gov } \\
\text { This publication is available from the NASA Center for AeroSpace Information, 443-757-5802 }\end{array}$} \\
\hline
\end{tabular}

\section{SUPPLEMENTARY NOTES}

\section{ABSTRACT}

A macro level finite element-based model has been developed to simulate the mechanical and impact response of triaxially-braided polymer matrix composites. In the analytical model, the triaxial braid architecture is simulated by using four parallel shell elements, each of which is modeled as a laminated composite. The commercial transient dynamic finite element code LS-DYNA is used to conduct the simulations, and a continuum damage mechanics model internal to LS-DYNA is used as the material constitutive model. The material stiffness and strength values required for the constitutive model are determined based on coupon level tests on the braided composite. Simulations of quasi-static coupon tests of a representative braided composite are conducted. Varying the strength values that are input to the material model is found to have a significant influence on the effective material response predicted by the finite element analysis, sometimes in ways that at first glance appear non-intuitive. A parametric study involving the input strength parameters provides guidance on how the analysis model can be improved.

\section{SUBJECT TERMS}

Polymer matrix composites; Braided composites; Finite element method; Micromechanics

\begin{tabular}{|c|c|c|c|c|c|}
\hline \multicolumn{3}{|c|}{ 16. SECURITY CLASSIFICATION OF: } & \multirow{2}{*}{$\begin{array}{l}\text { 17. LIMITATION OF } \\
\text { ABSTRACT } \\
\text { UU }\end{array}$} & \multirow{2}{*}{$\begin{array}{l}\text { 18. NUMBER } \\
\text { OF } \\
\text { PAGES } \\
28\end{array}$} & \multirow{2}{*}{$\begin{array}{l}\text { 19a. NAME OF RESPONSIBLE PERSON } \\
\text { STI Help Desk (email:help@sti.nasa.gov) } \\
\text { 19b. TELEPHONE NUMBER (include area code) } \\
\text { 443-757-5802 }\end{array}$} \\
\hline $\begin{array}{l}\text { a. REPORT } \\
U\end{array}$ & $\begin{array}{l}\text { b. ABSTRACT } \\
U\end{array}$ & $\begin{array}{l}\text { c. THIS } \\
\text { PAGE } \\
\text { U }\end{array}$ & & & \\
\hline
\end{tabular}



